9.

Derecho canónico 

Revista de Derecho

de la Pontificia Universidad Católica de Valparaíso

XXXVI (Valparaíso, Chile, 2011, $1^{\text {er }}$ Semestre)

[pp. $577-615]$

\title{
LA FORMACIÓN Y VALORACIÓN DE LA PRUEBA TESTIMONIAL EN EL PROCESO CANÓNICO DE NULIDAD MATRIMONIAL
}

["The Formation and Evaluation of the Testimonial Evidence in the Canon Process of Marriage Annulment"]

\author{
María Victoria Hernández Rodríguez* \\ Universidad Pontificia Salesiana, Roma
}

\begin{abstract}
RESUMEN
El derecho de los fieles al proceso y al consiguiente juicio justo, fundamentado en la verdad y, por tanto, en la caridad y en la prudencia, ha quedado establecido, por primera vez en la legislación eclesiástica, en el canon $221 \$ \$ 1-2$. A la búsqueda de la verdad va orientado el proceso, cuya fase probatoria constituye el corazón y el centro del mismo, ya que son las pruebas las que permitirán al juez obtener la certeza moral de la verdad sobre la existencia de un hecho controvertido. Entre los medios de prueba de los que se sirve el juez para encontrar la verdad están los testimonios, de cuya formación y eficacia vienen dadas algunas orientaciones, basadas también en la jurisprudencia de la Rota Romana, y teniendo en cuenta que el juez goza de libertad para valorar los medios de prueba, sin contradecir, no obstante, los principios
\end{abstract}

\begin{abstract}
The right of the congregation to the process and to the subsequent fair trial based on the truth and, therefore, on charity and prudence, has been established for the first time in the ecclesiastic legislation in canon $221 \$ \$ 1-2$. The proceeding is aimed at looking for the truth, probatory stage of which constitutes its heart and core, because the evidence will allow the judge to obtain the moral certainty of the truth over the existence of a controversial event. Among the evidence means the judge uses to find the truth are the testimonies; from their formation and efficacy some orientations, also based on the jurisprudence of the Roman Rota, arise, and bearing in mind that the judge is free to appraise the evidence means, without contradicting, though, the principles of logics, the maxim of experience and the scientifically
\end{abstract}

* Juez en el Tribunal de Apelación del Vicariato de Roma. Docente de Derecho Procesal Canónico en la Facultad de Derecho Canónico de la Universidad Pontificia Salesiana, Roma. Dirección postal: via Corfinio, 18, int. 2, 00183 Roma, Italia. 
de la lógica, las máximas de la experiencia y los conocimientos científicamente afianzados.

Palabras Clave

Verdad - Justicia - Sentencia - Prueba - Testimonio. grounded knowledge.

KEYWORDS

Truth - Justice - Ruling - Evidence

- Testimony.

[REcibido el 21 de abril y APROBADo el 9 de mayo de 2011].

\section{El DeReCho Del fiel AL JUICiO (CÁN. $221 \S 1$ CIC)}

1. El Código de Derecho Canónico ${ }^{1}$, al disponer en su canon $221 \S 1$ que "christifidelibus competit ut iura, quibus in Ecclesia gaudent, legitime vindicent atque defendat in foro competenti ecclesiastico ad normam iuris", reconoce al christifidelis, estableció - por primera vez en la historia de la legislación eclesiástica entre los derechos fundamentales del fiel (cánones 208-223 CIC) - un importante derecho subjetivo: el de acudir a los órganos jurisdiccionales eclesiásticos en demanda de tutela. El ejercicio de este derechodeber encuentra su fundamento en la salus animarum -fin sobrenatural al que tiende todo el ser y toda la actividad de la vida y misión de la Iglesia- y en la comunión de los fieles entre ellos y con la jerarquía. No es, sin embargo, un límite o una antítesis a la tutela judicial de los iura christifidelium el designio codificado de evitar los litigios, recurriendo a la reconciliación, a la pacificación, a la fraternidad que deben reinar en la Iglesia, actitudes mayormente acordes con la communio eclesial y por ello con la enseñanza del Maestro en Mt 5,40: "y al que te quiera llevar a juicio para quitarte la túnica, déjale también el manto”. Un consejo que incansablemente no ha dejado de repetir la legislación eclesiástica desde tiempos remotos hasta la legislación actual, donde son conocidas las normas que exhortan a todos los fieles, y en primer lugar a los obispos, a evitar las lites y a recomponerlas cuanto antes y fraternalmente, salva iustitia, indicando las vías idóneas a tal fin e incluso sirviéndose de personas competentes para la mediación ${ }^{2}$. Se deduce, pues, que el proceso y conexo juicio son una extrema ratio en la vida de la Iglesia, y que poco cuenta la solución de la lite si a esta no sigue una verdadera reconciliación entre las partes, es decir, entre los fieles y entre éstos y la Iglesia. Salva iustitia indica, por otra parte, la relación estrecha y armónica entre justicia,

${ }^{1}$ Ionnnes Paulus PP. II, Constitutio Apostolica Sacrae disciplinae leges, Codex Iuris Canonici promulgatur, Praefatio, Codex Iuris Canonici, Index, 25 ianuarii 1983, en $A A S .75$ (1983), Pars II, pp. VII-XIV, XV-XXX, pp. 1-301, pp. 303-317.[= CIC].

${ }^{2} \mathrm{Cfr}$. cánones $1146 \$ 1$ 1-2; 1676. Indirectamente, cánones 1713-1716; 1659. 
verdad y caridad, por lo tanto coartar el derecho del fiel a pedir justicia sería faltar a la verdad y a la caridad, sea que se trate de bienes privados, sea de bienes públicos. Mientras que en relación a los primeros, que pertenecen únicamente a los fieles, es por eso mismo posible y loable abdicar de ellos, cuando se trata de bienes de naturaleza pública, es decir, de aquellos bienes destinados a alcanzar el bien último de la salus animarum de los propios titulares y para evitar un eventual escándalo de la comunidad, no es posible disponer y renunciar a los mismo 3 .

Al derecho de acción se asocia el derecho al proceso y al juicio, derechos distintos pero consecuenciales entre ellos ${ }^{4}$ : en primer lugar, el proceso, seguidamente el juicio, producto del proceso, medio del que el hombre dispone para llegar al juicio. Sin proceso no es posible un juicio justo y equo $\mathrm{y}$, viceversa, sin juicio justo no es posible restablecer la justicia.

2. En torno a este derecho rotan derechos y deberes por parte del fiel y del órgano judiciario que, precisamente mediante el proceso y el juicio, deben conducir a la verdad, a la que se llega a través de la no poca fatiga que conlleva el proceso - "público acto de humildad" como lo describía Capograssi ${ }^{5}-$, por encima de pasiones y distracciones que puedan arrastrar y alejar de la misma ${ }^{6}$. Ciertamente, no será fácil pero tampoco imposible, porque el hombre es capaz de verdad, puede y quiere conocer la verdad, así lo ha declarado Benedicto XVI, en enero de 2006, al Cuerpo Diplomático

${ }^{3}$ Cfr. Juan Pablo II, "Discurso" a los Prelados Auditores, defensores del vinculo y abogados de la Rota Roma, 18 enero 1990, en AAS. 82 (1990), p. 876.

${ }^{4}$ Rodríguez-Ocaña, R., La tutela del derecho al proceso en las causas de nulidad matrimonial, en VILADRICH BATALLER, P. J. (editor), El matrimonio canónico ante el III milenio (Pamplona, 2001), pp. 1414ss.

${ }^{5}$ Capograssi, G., Intorno al processo. Ricordando Giuseppe Chiovenda, en Opere (Milano, 1959), V, p. 144.

6 "Esempio eccellente quanto altri mai è il processo di Gesù conclusosi con un giudizio $[. .$.$] cui seguì la condanna alla morte per crocifissione [. .$.$] qui non al processo è$ da addebitare la dolorosa conclusione, ma (se si vuole prescindere dalle misteriose ed altissime ragioni della Redenzione divina dell'uomo) all'uso distorto che ne fu fatto: equo formalmente, non lo fu nella sostanza. Non si deve infatti dimenticare che il processo è uno strumento nelle mani dell'uomo; serve di regola ai fini di giustizia, ma può anche essere veicolo di iniquità. Resta così confermata la necessità dell'equo processo e la profonda giustificazione della norma che lo sancisce e lo tutela; una necessità laica, politica, di retta conduzione della vita civile; la quale però, in quanto attinge alle radici profonde dell'umanità, deve essere intesa in tutta la sua sostanziale portata, e non in modo meramente formale": Lo CASTRO, G., Introduzione alla tavola rotonda sulla sentenza di Strasburgo del 20 luglio 2001, en El mismo., La sentenza della Corte Europea dei diritti dell'uomo del 20 luglio 2001 (Milano, 2004), p. 188. 
ante la Santa Sede ${ }^{7}$. El hombre, en efecto, con su propia razón es capaz de llegar a la verdad: el deseo de conocer es una característica común a todos los hombres, y gracias a la inteligencia de la que han sido dotados, creyentes o no creyentes, tienen la posibilidad de acudir a las fuentes profundas del conocimiento, que adquiere su sentido más pleno cuando es iluminado por la fe y por la Palabra de Dios ${ }^{8}$. La verdad - medio y fin- debe caracterizar el proceso y el juicio, que lo concluye.

En base a cuanto apenas expuesto, "si el proceso responde a la recta razón, no puede sorprender que la Iglesia haya adoptado la institución procesal para resolver cuestiones intraeclesiales de índole jurídica" 9 . Responder a la recta razón significa huir de los excesos del dogmatismo y del formalismo, significa no tener miedo al juicio, significa creer en la verdad ${ }^{10}$. Si la verdad no guía e invade el proceso, si no se alcanza y se emite un juicio verdadero no se restablece la justicia, ese dar a cada uno lo suyo, ese suyo que Dios ha conferido a cada uno ${ }^{11}$. Este gravoso munus corresponde principalmente al juez: declarar la voluntad del Legislador divino, no la suya propia.

${ }^{7}$ Benedicto XVI, “Discurso" al Cuerpo diplómatico acreditado ante la Santa Sede, 9 enero 2006, en $A A S .98$ (2006), p. 122.

${ }^{8}$ Ioannes Paulus PP. II, "Litterae encyclicae" Fides et ratio, 14 septembris 1999 , n. 31, en $A A S .91$ (1999), p. 29.

${ }^{9}$ Benedicto XVI, "Discurso" a los Prelados Auditores, defensores del vínculo y abogados de la Rota Roma, 28 enero 2006, en AAS. 98 (2006), p. 136.

${ }^{10}$ Cfr. Capograssi, G., cit. (n. 5), IV, p. 73.

${ }^{11} \mathrm{La}$ función del juez responde a una necesidad social: que cada hombre, cada institución tengan lo suyo, lo que les pertenece y corresponde. Si podemos clasificar de necesidad social el establecer una situación en la que cada uno tenga lo suyo es porque tal situación constituye un orden social, en el que cada cosa está en la justa relación respecto a su titular, lo que da lugar a un orden en la comunidad social, humana. Cualquier ruptura o alteración de esta correcta relación causa o provoca una anomalía, un desorden social: el orden injusto, la situación o las estructuras injustas. No se trata de un orden que satisfaga determinados deseos de los hombres, sino de un orden necesario para la persona y la sociedad. Esta armonía conserva la sociedad humana; corrompida, sin embargo, la destruye (DAnte, A., De Monarchia, [Augustae Taurinorum, 1853], II,5). Cicerón definió la justicia bajo el influjo de la filosofía estoica: dar a cada uno según su mérito y dar a cada uno lo que es suyo, siendo ambas definiciones equivalentes; en otros términos: tribuere e distribuere. De todas formas, hay que subrayar que en Cicerón aparece ya la expresión dar a cada uno lo suyo, que entrará definitivamente en la noción común de justicia. La definición más común de justicia conocida por su sencillez y no poca precisión la debemos a Ulpiano: "Iustitia est constans et perpetua voluntas ius suum cuique tribuendi” (Dig. 1,1,10). La justicia es la constante y perpetua voluntad de dar a cada uno su derecho (iuris praecepta): la constancia indica un hábito y, por lo tanto, significa una virtud; perpetua, obedece a la idea estoica según la cual las verdaderas virtudes duran siempre; voluntad indica aquí el acto de la voluntad, no la potencia (cfr. $S$. Theol, II-II, q. 58, a. 1 ad 1). Con Ulpiano, la fórmula de la justicia, 
Aparece, pues, clara la íntima y recíproca relación entre verdad y justicia, entre verdad y salus animarum, ley suprema en la Iglesia y ratio del juicio ${ }^{12}$, al punto que el compromiso por la verdad se convierte en el alma de la justicia.

A la verdad van ordenadas las formalidades procedimentales y respetadas no en sí mismas y por sí mismas, sino como garantía para la certeza del derecho y la verdad. El canon $221 \S 2$, que concierne no sólo a quien es llamado en juicio, parte demandada, sino también a quien tiene la iniciativa, parte actora, establece el derecho a ser juzgado según las disposiciones de ley, que deben ser aplicadas con equidad ${ }^{13}$, criterio hermenéutico para cualquier norma procedimental y principio que hace presente la verdadera justicia, la justicia divina que es caridad ${ }^{14}$. De dicha aplicación de las normas procedimentales

además de ganar en precisión, adquiere la dimensión jurídica porque especifica que el suyo de cada uno es su derecho. Especificación, puntualización ya contenida en la definición de Aristóteles, que Ulpiano hace más explícita; en efecto, la definición de Ulpiano expone mejor que las precedentes definiciones un punto capital de la teoría de la justicia: la primacía del derecho sobre la justicia, o, en otras palabras, que la justicia está en función del derecho y no al contrario; la justicia presupone el derecho. Si la justicia consiste en dar a cada uno su derecho, es obvio que para que haya acción justa -propia de la justicia- es necesario que exista el derecho, respecto del cual se es justo. Por eso San Isidoro de Sevilla escribirá que se dice justo de una persona porque respeta los derechos y vive según la ley (“iustus dictus quia iura custodit et secundum legem vivit", en Etymologiarum sive originum [Oxford, 1911, repr. 1989], libri XX, X, 124).

${ }^{12}$ Sobre la salus animarum como fin de la Iglesia y del ordenamiento canónico, véase. Herránz, J., Salus animarum, principio dell'ordinamento canonico, en Ius Ecclesiae 12 (2000), pp. 291 ss. Arrieta, J. I., La salus animarum quale guida applicativa del diritto da parte dei pastori, en Ius Ecclesiae, 12 (2000), pp. 343 ss. BerTOLOne, V., La salus animarum nell'ordinamento giuridico della Chiesa (Romae, 1987).

${ }^{13} \mathrm{El}$ derecho canónico tiene ante todo que evitar al hombre el pecado, y la equidad consiste precisamente, según la nota definición del Hostienses, en asegurar el reino de los elementos espirituales y su preponderancia; por tanto, la equitas canónica proviene del carácter espiritual del derecho canónico y se apoya sobre la base profunda que hace prevalecer el bien o el interés espiritual de las almas sobre cualquier otra consideración más humana o terrena, cfr. Lefebvre, Ch., Aequitas canonica et periculum animae dans la doctrine de l'Hostiensis, en Ephemerides Iuris Canonici, 8 (1952), pp. 305-321. A propósito de equitas, véase Lefebvre, Ch., Equité, en Dictionnaire de Droit Canonique (Paris, 1953), V, coll. 394-410; EL MISMO, Equité canonique et manifestations de volonté, en Actes du Congrès de Droit Canonique (Paris, 1947), pp. 339-347; Fedele, P., Equità. Equità canonica, en Enciclopedia del Diritto (Milano, 1966), XV, pp. 147160; El mismo, "Nibil aliud est aequitas quam Deus", en Ephemerides Iuris Canonici, 20 (1964), pp. 189-207; HERVADA, J., Il diritto naturale nell'ordinamento canonico, en Ius Ecclesiae, 1 (1989), pp. 493-508.

${ }^{14}$ Bertone, T., La Chiesa e l'impegno per la giustizia. Legalità, giustizia, moralità, en La giustizia nella Chiesa. Fondamento divino e cultura processualistica (Città del Vaticano, 1997), p. 14. 
debe ser garante el juez, en quien tienen que resplandecer la fidelidad a la ley, la profesionalidad y la competencia para tutelar los derechos ad normam iuris con imparcialidad e independencia, equidistante, por tanto, de las partes; la misma certeza moral que debe obtener el juez para pronunciar una sentencia ${ }^{15}$ no es sino expresión del servicio a la verdad ${ }^{16}$.

${ }^{15}$ La certeza es esa cualidad del conocimiento encarnada por una adhesión firme y segura del intelecto a la verdad acerca de un hecho en controversia y al derecho a esto aplicable, que el juez tiene que alcanzar como consecuencia de las pruebas llevadas a cabo en juicio: "certitudo nibil aliud est quam determinatio intellectus ad unum" (S. Thomas Aguinatis, Opera omnia: In quattuor libros sententiarum, 1. 3, d. 23, q. 2, a. 2c) o en otras palabras: "certitudo proprie dicitur firmitas adhaesiones virtutis cognitivae in suum cognoscibile” (1. 3, d. 26, q. 2, a. 4). La compleja categoría jurídica de la certeza moral ha sido objeto de una fundamental y decisiva intervención del magisterio pontificio de Pío XII, el cual, retomando algunos puntos de una precedente alocución suya a la Rota Romana del 3 de octubre de 1941, el 1 de octubre de 1942 pronunció en manera magistral el principio que nos ocupa: PIo XII, "Alocución" a la Rota Romana, 1 octubre 1942, en $A A S .34$ (1942), pp. 339-340. Juan Pablo II retomará así mismo el argumento en el anual discurso a la Rota Romana el 1 de febrero de 1980, recordando textualmente las palabras de Pío XII y aclarando que, cuanto expuesto en el discurso de su Predecesor, correspondía en modo auténtico al concepto canónico de certeza moral, en $A A S .72$ (1980), p. 176. Se vea también Grocholewski, Z., La certezza morale come chiave di lettura delle norme processuali, en Ius Ecclesiae, 9 (1997), pp. 424 ss.

${ }^{16}$ No es fácil de precisar en qué consista esta descripción del juez. Quizás no se aleja demasiado y se identifica con la capacidad del juez eclesiástico de juzgarse a sí mismo y de juzgar a su tiempo, explicaba S.E. Mons. Pompedda. Ante todo, la capacidad de juzgar a sí mismo (insiste particularmente sobre ello el Decretum de Graciano: cfr. C. III, q. 7, c. 3: "Qui aliorum vicia puniunt sua prius corrigere studeant"; c. 4: "Ille de vita alterius iudicet, qui non habet in se ipso quod puniat"; c. 5: "Gravatus criminibus aliena iudicare non valet"; c. 6: "Primum nosmetipsos, deinde proximos debemus corrigere"; c. 7: "Sacerdos prius sua peccata, deinde aliena detergat". Esta madurez humana e intelectual significa serenidad de juicio, que consiste en la "capacità di agire e giudicare distaccandosi da proprie e personali vedute e opinioni, di giudicare astraendo da ogni pregiudizio sia generale sia particolare, riferito cioè al caso; di saper astrarre da considerazioni umane, politiche e sociali; di saper accettare anche l'altrui opinione pur contraria alla propria (mostrando, ad esempio, distacco di fronte ad una sentenza di appello che riformi la propria); di saper accettare in fase di camera di consiglio il parere della maggioranza, o magari del più giovane; di saper affrontare e confrontare le ragioni degli altri colleghi senza prevenzione o chiusura di sorta; e infine e soprattutto di sapersi arrendere davanti agli atti e a quanto provato, senza mai piegare, attraverso artifici istruttori apparentemente legali [...] gli stessi atti secondo una propria teoria preconcetta o particolare impostazione, ricordandosi sempre che se è lui a dare la decisione finale, egli non è comunque l'unico essenziale protagonista del processo canonico, nel quale si impone [...] il rispetto dei differenti ruoli”: Pompedda, M. F., Il giudice nei tribunali ecclesiastici: norma generale e caso concreto (funzione, competenza professionale, garanzie di indipendenza, giudici laici), en La giustizia nella Chiesa: fondamento divino e cultura processualistica moderna (Città del Vaticano, 1997), pp. 142-143. "De cette étude 


\section{VERDAD Y ACTIVIDAD PROBATORIA}

1. Puesto que el proceso canónico constituye esencialmente un juicio, es comprensible que la prueba, de por sí, se refiera a todos los elementos sobre los que el juicio mismo recae. En consecuencia, es absolutamente necesario un profundo y completo conocimiento de la cosa objeto de la lite, que deberá ser juzgada. La fase de instrucción o probatoria del proceso, recogida de las pruebas producidas por las partes o ex officio, está dirigida y orientada a alcanzar ese conocimiento de la verdad.

Es esta una fase esencial que va precedida de la fase introductoria, en la cual vienen definidos los términos de la controversia y en concreto el capítulo de nulidad matrimonial acusado. Es, pues, de capital importancia la individuación correcta del capítulo de nulidad, sea porque debe corresponder y reflejar la verdad sobre la historia matrimonial y personal y sobre las intenciones y la voluntad matrimonial de las partes que se someten a examen, sea porque el tribunal colegial que tendrá que emitir el juicio final deberá atenerse y responder estrictamente a cuanto es formulado en la concordancia de la duda. No será inútil recordar que la entera fase instructoria tiene que mirar a recoger todos los elementos necesarios para responder a los requisitos de prueba relativos al capítulo de nulidad acusado, requisitos determinados por la norma jurídica y elaborados por la jurisprudencia rotal.

En esta fase instructoria, se requiere la máxima pericia del juez, su preocupación pastoral ${ }^{17}$ para conseguir que mediante la corresponsabilidad de

psychologique que le juge fera sur lui-même, la première et essentielle conclusion est que, pour juger les autres, il doit avant tout renoncer à son moi mauvais: amour propre, paresse, intérêt personnel, préjugés; trop bonne opinion de soi-même, source de tant de nos errements; sensibilité déréglée avec ses antipathies ou ses sympathies, fussent-elles pour la loi, mais au détriment de l'impartialité. Il doit impitoyablement retrancher, comprimer toutes ces imaginations qui entravent le jugement droit": Jullien, Card. A., Juges et avocats des Tribunaux de l'Église (Rome, 1970), pp. 265-266. Se vean también las iluminadoras observaciones de FELICI, P., Indagine psicologica e cause matrimoniali, en Communicationes, 5 (1973), pp. 105-106. Por otro lado, forma parte también de la madurez personal del juez su capacidad de juzgar a su propio tiempo. Esto, en efecto, no es simplemente reconducible al conocimiento de hechos y acontecimientos, porque se trata de conocer la cultura -con la imprescindible referencia antropológica y con sus manifestaciones más ordinarias- del propio tiempo. No tanto de oídas, sino porque participa de ella: cfr. PompedDA, M. F., Il giudice, cit. esta nota, pp. 142-143. El mismo, Decisione-sentenza nei processi matrimoniali: del concetto e dei principi per emettere una sentenza ecclesiastica, en EL MISMO, Studi di diritto processuale canonico (Milano, 1995), p. 188.

${ }^{17}$ Ello no significa, en esta fase ni tanto menos en la decisoria, una falsa misericordia que caiga en un diagnóstico equivocado, i n v e $\mathrm{n} t$ a $\mathrm{n} d$ o una nulidad para cada caso matrimonial naufragado, pensando, erróneamente, de tranquilizar la conciencia de las 
todos los que intervienen en el proceso y en el respeto de los instrumentos legales que el Código de Derecho Canónico, en el libro VII, ha determinado al fin de un ecuo y justo proceso y juicio desde el punto de vista procedimental y por lo tanto substancial, en otras palabras de las normas procesuales y de las garantías procedimentales.

2. Sobre la verdad puesta en luz durante la fase instructoria tiene que apoyar la certeza moral, fundamento del juicio, y esa misma certeza tiene que reflejar perfectamente la verdad. Una certeza que el juez tiene que obtener y alcanzar in iure et in facto, donde in facto equivale a la fórmula canónica ex actis et probatis. Esa certeza debe quedar reflejada a su vez en la motivación de la sentencia, de modo tal que sea comprensible a las partes, para quienes la sentencia tiene función de ley ${ }^{18}$, demostrando así respeto hacia las mismas ${ }^{19}$

partes. Esta actitud se extiende también a todos aquellos que participan en el proceso: abogados, testigos, partes públicas. En 1994, Juan Pablo II se dirigió a los Auditores de la Rota Romana recordando magistralmente la relación entre el esplendor de la verdad y la justicia, corroborando así el discurso que le había dirigido el Decano Mons. Pompedda: "¿qué justicia... podría ser llamada tal y pretender un semejante apelativo si no se basara, si no correspondiese, si no fuese reflejo de la verdad?" (L'Osservatore romano, 28 enero 1994, p. 5; AAS. 86, [1994], p. 948). Es también un derecho de las partes el de no ser engañados con una sentencia de nulidad que esté en contrasto con la existencia de un verdadero matrimonio. La caridad y la misericordia no pueden prescindir de la exigencia de la verdad, IoAnnes PAulus PP. II, Litt. Enc. Veritatis splendor, 6 augustii 1993, nn. 104-105, en $A A S .85$ (1993), pp. 1133. En su último discurso a la Rota Romana, Juan Pablo II insistió nuevamente en el hilo conductor de este nuestro argumento: "La deontología del juez tiene su criterio inspirador en el amor a la verdad. Así pues, ante todo debe estar convencido de que la verdad existe. Por eso, es preciso buscarla con auténtico deseo de conocerla, a pesar de todos los inconvenientes que puedan derivar de ese conocimiento. Hay que resistir al miedo a la verdad, que a veces puede brotar del temor a herir a las personas. La verdad, que es Cristo mismo (cf. Jn 8, 32 y 36), nos libera de cualquier forma de componenda con las mentiras interesadas", y con extrema claridad y honor a la verdad proseguía el Romano Pontífice: "El juez que actúa verdaderamente como juez, es decir, con justicia, no se deja condicionar ni por sentimientos de falsa compasión hacia las personas, ni por falsos modelos de pensamiento, aunque estén difundidos en el ambiente. Sabe que las sentencias injustas jamás constituyen una verdadera solución pastoral, y que el juicio de Dios sobre su proceder es lo que cuenta para la eternidad", en $A A S .97$ (2005), p. 65.

${ }^{18}$ Usando una expresión de Santo Tomás de Aquino podemos decir que la sentencia es casi una ley particular acerca de un determinado hecho particular (Sum. Theol., II-II, q. 67, a. 1). Efectivamente, el Código de Derecho Canónico, en el canon $16 \$ 3$, hablando de la sentencia judicial en la sección de la interpretación de la ley, dispone que "ligat personas atque afficit res pro quibus data est".

${ }^{19}$ Partes que no son sólo las dos contendientes, sino también el defensor del vínculo y el promotor de justicia, si ha intervenido, por lo que la Instrucción Dignitas 
y explicando para ello en modo exhaustivo las razones del dispositivo, al mismo tiempo que evidencia la seriedad del trabajo de quienes han emanado el juicio y, por qué no, de quien ha redactado la ponencia.

Entre los requisitos fundamentales o basilares para el pronunciamiento de una sentencia no hay duda de que el primero de ellos concierne a la existencia de una parte que instaure la acción, ya que, en base al Derecho romano, nemo iudex sine actione. En efecto, el canon 1501 establece "iudex nullam causam cognoscere potest, nisi petitio, ad normam canonum, proposita sit ab eo cuius interest, vel a promotore iustitae", consagrando el ya mencionado principio romano. La iniciativa es, pues, de una parte diferente del juez ${ }^{20}$. Sin embargo, en el canon $1452 \$ 1$ el Supremo Legislador afirma que el juez puede, es más debe actuar ex officio una vez introducida o instaurada la lite en concreto cuando está en juego el bonum publicum o la salus animarum. Es, por tanto, condición indispensable la manifestación de la voluntad de un individuo, el cual a su vez debe haber la capacidad jurídica de actuar en juicio, es decir, de pedir la actualización de la ley en un caso particular: "nibil aliud est actio quam persequendi iudicio quid sibi debetur" (Iust. Inst. IV,6 pr. $)^{21}$. Por otra parte, requisito también basilar es la potestad judicial, la competencia jurisdiccional del juez ${ }^{22}$. Establecidas la competencia del juez y la capacidad de estar en juicio de las partes, debe ser determinado el objeto de la controversia.

La determinación del objeto en la litis contestatio sirve no sólo como guía en la instrucción de la causa ( $y$ en consecuencia para llegar a una investigación profunda e informativa de la controversia), sino que es el principal requisito de la naturaleza inherente a la misma sentencia. El canon $1513 \$ 1$

connubii ha establecido, en conformidad con el canon 1617, que el decreto con que la decisión afirmativa viene confirmada deba expresar, bajo pena de nulidad, al menos sintéticamente los motivos y además dar una respuesta a las animadversiones del defensor del vínculo: Pontificium Consilium de legum textibus, Dignitas connubii. Instructio servanda a tribunalibus dioecesanis et interdioecesanis in pertractandis causis nullitatis matrimonii (Romae, 25 ianuarii 2005). [= DC.], artículo $265 \$ 4$.

${ }^{20} \mathrm{El}$ canon 1674 afirma quienes son capaces de acusar el matrimonio, cfr. cánones 1679 e 1620 n. 4.

${ }^{21}$ Capacidad jurídica que en sede procesal se denomina capacitas in iudicio agendi: el fiel, en cuanto titular de un bien o derecho, puede tutelarlo en vía judicial. La capacitas in iudicio agendi constituye un primer nivel de capacidad jurídica sensu lato; un segundo nivel está constituido por la capacidad de actuar, entendida como capacidad procesual definida por el Código como capacitas in iudicio standi; en fin, el tercer nivel se refiere a la capacidad jurídica que mira a la actuación del derecho de defensa o capacitas postulandi.

${ }^{22}$ Cfr. Pinto Gómez, J. M., La giurisdizione, en Bonnet P. A.-Gullo C. (editor), Il processo matrimoniale canonico (Città del Vaticano, Libreria Editrice Vaticana, 1994, nuova edizione riveduta e ampliata), pp. 101-132. 
completado con el canon 1514 nos indica cómo la determinación del petitum procesal sea esencial en cualquier tipo de proceso, sea contencioso, sea penal. El canon 1514 atenúa el rigor del principio establecido en el mismo, es decir, la prohibición rigurosa de modificar los términos de la controversia, a no ser mediante un nuevo decreto, per causa grave, a instancia de una parte y oídas las razones de las otras ${ }^{23}$. La modificación está subordinada a unas condiciones y no es iniciativa del juez, que está obligado, bajo pena de nulidad de la sentencia, a no pronunciarse infra petita partium, ni extra petita partium ni ultra petita partium. La formulación de la duda con la petición de las partes condicionará, por tanto, la respuesta del juez.

La sentencia presupone, en síntesis, una petición judicial, debe responder a la cuestión tratada en el curso de la fase de instrucción, y debe resolverla pronunciándose acerca del objeto de la controversia. La sentencia es, así, una respuesta a una cuestión que ha sido jurídicamente tratada; en otras palabras, no es posible una sentencia donde no se haya dado un proceso y donde las normas fundamentales de todo proceso no hayan sido observadas. Esto se comprende sólo en relación al contradictorium y a la posibilidad de defensa dada a todas las partes que intervienen en el proceso. Según la ley canónica, la sentencia no sólo debe ser conforme al escrito de demanda, tiene que ser también conforme a las actas judiciales puesto que la petición judicial inicia sí con la presentación y aceptación de la demanda, pero no se concluye en estos actos, ya que las pruebas en muchos casos trascienden la exposición presentada en la demanda.

3. Para pronunciar, se exponía al inicio de esta sección, una sentencia, el canon $1608 \$ 1$ establece que el juez haya alcanzado la certeza moral sobre aquello que debe decidir. El $\$ 1$ nos indica cuáles son las fuentes de la certeza: las actas y cuanto se ha demostrado; mientras que el $\$ 2$ se dirige al juez, dejando a su conciencia el examen de las pruebas, a excepción de las disposiciones de la ley sobre la eficacia de algunas de ellas. En otras palabras, una vez que la información se ha producido, las nuevas reglas de la prueba facultan al juez para valorarla de acuerdo a las reglas de la sana crítica. Esto significa que el juez tiene libertad para valorar los medios de prueba, pero teniendo como límite no contradecir los principios de la lógica, las máximas de la experiencia y los conocimientos científicamente afianzados. Al hacerlo, el juez deberá expresar las razones jurídicas y las simplemente lógicas, científicas, técnicas o de experiencia, en cuya virtud les asigne valor o las desestime.

${ }^{23}$ Llobell, J., La modificación ex officio de la fórmula de la duda, la certeza moral y la conformidad de las sentencias en la instrucción Dignitas connubii, en Ius canonicum, 46 (2006), pp. 140-146. En favor de una posición diferente, véase Pompedda, M. F., Studi di diritto processuale canonico (Milano, Giuffrè Editore, 1995), p. 172. 
En efecto, en el proceso eclesiástico el formalismo jurídico no ocupa un lugar primordial, no es considerado un principio guía en el proceso. Es fundamental, sin embargo, la libre valoración de las pruebas. El juez tiene que decidir según el propio y libre convicción y conocimiento y según la propia conciencia si las pruebas producidas y la investigación llevada a cabo sean o no suficientes para alcanzar la necesaria certeza moral sobre la verdad y la realidad de la causa en proceso, que el canon $1608 \$ 1$ le impone como requisito para emitir un juicio.

El pronunciamiento del juez va precedido de una fase deliberativa, esa íntima operación del espíritu dispuesta a llegar a la certeza moral en base a las actas y a cuanto ha sido probado. Ciertamente, se encontrará a veces con pruebas inciertas, pero la duda sólo puede tener dos efectos en el juez, como afirmaba S.E. Ewers, decano de la Rota Romana en su prolusión académica de 1978: en un espíritu débil y perezoso, lleva a la negligencia; en un espíritu que no renuncia a la búsqueda de la verdad, se convierte en un impulso ulterior al descubrimiento de la verdad ${ }^{24}$.

Sobre el libre convencimiento es necesaria alguna ulterior observación. La libertad de valoración de las pruebas es una exigencia del derecho divino, vinculada a un criterio de racionalidad que excluye por tanto cualquier apreciación arbitraria. A propósito de este particular, es necesario distinguir las reglas que se refieren al correcto desarrollo y ejercicio de la función judiciaria de aquellas atinentes a la valoración de las pruebas, efectivamente confiada al libre discernimiento del juez. El magisterio pontificio ha intervenido afirmando que si es verdad que el juez debe actuar conforme al juicio de la propia conciencia, es igualmente verdad que el juicio de la conciencia no puede pretender de establecer la ley; puede solamente reconocerla y hacerla propia $^{25}$.

La convicción del juez está pues limitada por algunas reglas: debe formarse no libremente sino ex actis, lo que significa que al juez está prohibido servirse de elementos de conocimiento y de prueba extraprocesales, como establecido en el canon $1604 \$ 1$. En fuerza de este principio basilar, el juez, al que las partes y sus defensores por prohibición no pueden dar informaciones de las que no quede rastro en actas ("quod non est in actis non est in mundo"), está obligado a fundar su decisión únicamente ex actis, que abraza desde las actas judiciales o procesales a las actas de causa.

El juez debe construirse su convicción ex probatis, no solo sobre lo que ha sido afirmado sino exclusivamente sobre lo que resulte probado en orden

${ }^{24}$ S.E. Ewers, Prolusio academica in novo inchoando anno apud Studium Rotale, 6 novembre1978, en Monitor Ecclesiasticus, 103 (1978), pp. 381-386.

${ }^{25}$ Ioannes Paulus PP. II, Ad Romanae Rotae iudices, 10 februarii 1995, en $A A S$., 87 (1995), p. 1.017. 
a la verificación del hecho principal. En otras palabras, no están permitidas al juez construcciones arbitrarias fundadas en la fantasía personal. Debe atenerse a las pruebas legales ${ }^{26}$.

En caso de duda, es decir, de imposibilidad de alcanzar la certeza moral y de emitir una sentencia que dé razón a la parte actora, es una regla de juicio la indicada en el can. $1608 \S 4$ : en caso de una causa que goce del favor iuris, como son las causas de declaración de nulidad del matrimonio, el juez deberá declarar que no consta, es decir, tiene que pronunciar non constare de nullitate matrimonii.

\section{LA PRUEBA TESTIMONIAL}

1. Es el momento de dirigir la atención directamente al argumento objeto del presente estudio.

El título $4^{\circ}$ : De probationes, de la parte II del libro VII CIC., trata de la prueba, ese acto judicial por medio del cual en forma legítima se dan al juez argumentos idóneos sobre una cosa dudosa o controvertida. De ahí se comprende bien cómo la fase probatoria constituya el corazón y el centro del juicio, ya que son las pruebas, repetimos, las que permiten al juez obtener la certeza moral de la verdad sobre la existencia de un hecho controvertido.

El Código ofrece una serie de pruebas, como las declaraciones de las partes ${ }^{27}$,

${ }^{26}$ Cfr. Ioannes Paulus PP. II, Ad Romanae Rotae iudices, 1 februarii 1980, en $A A S ., 72$ (1980), p. 175.

${ }^{27}$ Mientras que en el Código de Derecho Canónico del 1917 las declaraciones de las partes no estaban incluidas entre las pruebas, el Código vigente ha querido inserirlas porque las deposiciones de las partes, actor y demandado, pueden ser un auxilio precioso al juez con el fin de obtener un conocimiento más completo y preciso de la controversia sometida a su examen y en orden, sobre todo, a obtener la verdad y la certeza moral en el momento de decidir la causa. El Código, sin embargo, deja a la discreción del juez la facultad de interrogar a las parte, en base al canon 1452, supliendo así la negligencia de las mismas partes y en general en la presentación de las pruebas, pero sólo en el proceso contencioso y en el penal. Recuerda la obligación de convocar a las partes en dos circunstancias: si la parte lo solicite (y por parte debe entenderse partes privadas y públicas) o si la declaración de la parte sea útil para probar un hecho, cuyo acertamiento tenga un interés público, como por ejemplo las causas de nulidad del matrimonio, en las que las partes tienen que ser siempre interrogadas. La parte que es llamada legítimamente a declarar, es decir, a norma de ley, está obligada a responder, a decir la verdad, toda la verdad y nada más que la verdad (cfr. canon 1531). Tal obligación no se le pide al imputado en las causas penales (cfr. canon $1728 \$ 2$ ), sea por derecho divino que humano, pero no significa que pueda mentir en lugar de decir la verdad. Si la parte se niega a responder, corresponde al juez valorar los motivos. No existen, sin embargo, sanciones al silencio o rechazo de la parte, como eran previstas en el Código abrogado. $\mathrm{Ni}$ siquiera es ya obligatorio el juramento de decir de la verdad; hoy el Código establece 
los documentos ${ }^{28}$, las deposiciones de los testigos, la prueba

que en los casos en los que está en juego el bien público, el juez tiene que hacer prestar juramento a las partes, pero estas, por una causa grave, pueden negarse a hacerlo. En las causas que, al contrario, vierten sobre un bien privado, se deja a la discreción del juez. El tipo de juramento es el de veritate dicenda, que tiene solo valor subjetivo de prueba; además del juramento de veritate dicenda, el Código vigente ha conservado la fórmula de veritate dictorum. A estas dos modalidades de juramento están obligados los testigos, a las que se añade el juramento de secreto servando (cfr. canon $1562 \$ 2$ ). Sobre la modalidad del examen, de proponer las preguntas, etc. se reenvía, en fuerza del canon 1534, a las normas establecidas para los testigos en los cánones $1548 \$ 2$ n. 1, 1552, 1558-1565. Para una síntesis sobre las declaraciones de las partes, puede consultarse CABERLETTI, G., Le dichiarazioni delle parti, en Bonnet, P.A.; Gullo, C. (editor), Il giudizio de nullitá matrimoniale dopo l'istruzione Dignitas connubii, III: Parte dinamica del processo (Città del Vaticano, Libreria Editrice Vaticana, 2008), pp. 343-360.

${ }^{28} \mathrm{El}$ documento es, en sentido propio una escritura, dirigida a probar en juicio la verdad de una afirmación, la legitimidad de un derecho, la existencia de un hecho de naturaleza y de contenido jurídico. Esta prueba documental, el Código de 1983 la ha introducido antes de la prueba testifical, probablemente para evidenciar el valor de imparcialidad y de consistencia que tienen las pruebas escritas, no modificables voluntariamente y creadas en tiempo no sospechoso, es decir, anteriores al proceso. Algunos autores consideraban fuese voz muerta: "Dignior et aestimabilior est vox viva quam mortua..." mientras "probatio per testes est vera et naturalis, per instrumenta straordinaria et artificialis" (REINFFENSTUEL, A., Ius canonicum universum [Venetiis, 1759], II, tit. $27^{\circ}$, p. 309 , n. 286). Los documentos públicos tienen la garantía de la ley, mientras los privados están vinculados a la autoridad personal de quien los ha redactado o suscrito. Los documentos públicos eclesiásticos y civiles dan fe en los juicios ex se y contra todos, pero solo en aquellas cosas que afirman directa y principalmente: directamente en cuanto que forman el objeto del documento, y principalmente, en cuanto que se refieren a la sustancia del acto jurídico del que trata el documento. Estos elementos secundarios tienen o pueden tener solo valor indiciario. Contra los documentos está admitida la prueba contraria, es decir, la impugnación de la validez de su contenido, de la legalidad de la forma, de su integridad, etc. Por tanto, la fuerza probatoria del documento público es impugnable con argumentos evidentes y contrarios, que hagan caer la presunción de derecho a su favor. Para que un documento privado tenga fuerza de prueba tiene que ser reconocido por la parte contra la cual se presenta, y debe ser admitido por el juez (canon 1542). Por eso, el canon 1542, en su primera parte, equipara los documentos privados a la confesión extrajudicial en relación a quien lo ha redactado o suscrito y de los que intervienen en causa: corresponde por ello al juez la valoración del documento, teniendo en cuenta todo el conjunto de las pruebas, perpensis omnibus adiunctis. Así mismo, corresponde al juez qué valor dar a un documento defectuoso, sea público que privado y si es necesaria la intervención de un perito o experto. El canon 1546 establece cuáles son los documentos que la parte no está obligada a presentar, o bien, está exenta de ello. En el ejercicio de su poder, la Iglesia no se preocupa sólo de la justicia sino de evitar daños a las personas, y ateniéndose a los principios de orden moral, dispone que nadie está obligado a producir en juicio documentos si dicha presentación puede ser causa de infamia, vejaciones u otros graves daños a sí mismo o a terceros, 
pericial $^{29}$, el reconocimiento judicial y la inspección ${ }^{30}$, las presunciones ${ }^{31} \mathrm{y}$,

o bien, puede conllevar el peligro de violación de un secreto que se tiene obligación de respetar. En este sentido, es posible transcribir una parte reducida del documento y exhibirla en copia autenticada para obviar a los inconvenientes indicados.

${ }^{29} \mathrm{La}$ pericia es una prueba judicial más bien tardía en el proceso procesual. Su importancia ha aumentado mucho en nuestros tiempos, debido al progreso de la técnica y de las ciencias, que pueden ofrecer una aportación preciosa para conseguir la certeza moral y, por tanto, la recta administración de la justicia. Es tarea del perito acertar la verdad objetiva de un hecho acaecido, pero nunca pronunciarse sobre el mérito de la causa (canon $1577 \$ \$ 1-2$ ). El es sólo un experto designado ex officio o por la parte para ofrecer al Tribunal su colaboración mediante un parecer técnico sobre la existencia y sobre la naturaleza de un hecho al que él mismo es ajeno, o sobre otras cuestiones que el juez haya considerado necesario someter a su valoración y juicio profesional. Se debe recurrir a la prueba pericial siempre que, por disposición del derecho o del juez, el objeto del juicio sea tal que requiera el examen y el parecer o voto de una persona experta, fundado todo sobre los principios de la ciencia y de la técnica, en el respeto de los principios antropológicos cristianos, si se tratara de una cuestión de carácter psicológico. La intervención del perito está prevista en particular por el canon 1680 relativamente a las causas para la declaración de nulidad del matrimonio. Sobre este argumento de prueba, Gullo, C., Iperiti ele perizie, en Bonnet, P.A. - Gullo, C. (editores), Il giudizio, cit. (n. 27), pp. 425-440.

${ }^{30}$ Reconocimiento judicial e inspección (cánones 1582-1583) son dos medios diferentes de prueba, que no tienen normalmente espacio en los procesos de nulidad matrimonial.

${ }^{31}$ Los hechos corroboran las palabras de las partes y de sus testigos; por ello mismo el juez puede construir la prueba indirecta o de las presunciones, siempre que esta se base sobre factores ciertos y confluentes que tienden hacia una dirección individual y unívoca (POMPEDDA, M. F., De usu praesumptionum contra matrimonium valorem, en L'Année canonique, 22 [1978], pp. 33-41). Este principio vale también para las causas que conciernen al bien público. Según la jurisprudencia rotal, de un conjunto de conjeturas probables puede derivar una conclusión moralmente cierta, que, considerada individualmente, no ofrece una plena demostración y que podría ser explicada en otro modo; una presunción grave puede a menudo derivar de tales conjeturas, y como tal, evidentemente, debe ser considerada apta a constituir una prueba plena (Ibid,36ss). En sede de reforma del Código, sobre este tipo de prueba, las presunciones, fue propuesta su total supresión porque se trataría de cánones de carácter doctrinal, y por tanto aparecía suficiente cuanto dispuesto en el canon $1526 \$ 2$, 1: “non indigent probatione quae ab ipsa lege praesumuntur". Sin embargo, puesto que en los cánones redactados no faltaban disposiciones positivas, se decidió mantener esta prueba, cfr. Communicationes 11 (1979), p. 127. No falta algún autor que no considera la presunción una regla de prueba tendente a la formación de la convicción del juez, sino un criterio que la legislación le da para suplir la falta de la misma. Al respecto, véanse: ReIfFenstuel, A., Ius canonicum universum, cit. (n. 28), II, p. 235; Del Amo, L., Ad can. 1585, en Lombardia, E. Arrieta, J. I. (editores), Codice di diritto canonico (Roma, 1986) III, p. 1147; Pinto, P.V., I processi nel Codice di diritto canonico. Commento sistematico al lib. VII (Città del Vaticano, Libreria Editrice Vaticana, 1993), p. 273; Jullien, A., Juges et avocats des 
por otra, la valoración subjetiva (ex coscientia) por parte del juez, que es en definitiva el último responsable del pronunciamiento justum y, en cuanto tal, es iustitia animata.

Fijamos la atención en la prueba testimonial de la que puede derivar la certeza moral, incluso cuando se trata de un solo teste.

El derecho canónico ha tenido siempre en grande estima la prueba testifical. Es más, se podría decir que es una característica del proceso canónico en comparación con el proceso civil moderno e incluso con el derecho romano justinianeo, que tenía una actitud menos favorable hacia los testigos. Es bien conocido que el derecho procesal canónico se ha construido en su mayor parte con materiales provenientes del derecho romano ${ }^{32}$.

tribunaux de l'Église (Roma, 1970), p. 286. “Certitudo quaedam anticipata, coniecturalis et provisoria circa existentiam alicuius facti, propter certas rationes”: es la definición dada por la doctrina y prácticamente aceptada por la legislación en cuanto que es muy clara y en función de la práctica de la prueba judicial; la presunción es, pues, una conjetura o suposición probable de una cosa incierta, como establecido en el can. 1584. Se presenta como una prueba sui generis, porque la ley establece que determinados actos llevan a conclusiones que prueban una cosa dudosa. A las presunciones determinadas por la ley (ab iure) y a aquellas formuladas por el juez (praesumptio hominis) hay que añadir las presunciones de la doctrina y de la jurisprudencia, que tienen su importancia sobre todo en las causas para la declaración de nulidad del matrimonio. Ninguna escapa al principio de contradictorio, puesto que pueden ser canceladas por la prueba contraria. La instrucción Dignitas connubii, en la última sección del capítulo II sobre Las presunciones (artículos 214-216), dedica un solo artículo sin la correspondiente disposición en el CIC. El artículo $216 \$ 2$ determina que para evitar abusos; cfr. Decreto del 13 diciembre 1995 del Supremo Tribunal de la Signatura Apostólica, en Periodica, 85 (1996), pp. 531-534, y comentario de U. Navarrete, pp. 535-548. De acuerdo con las prescripciones del canon 19 y del artículo 126 de la Pastor Bonus, en materia de presunciones formuladas por el juez, este no puede formular presunciones discordantes con aquellas elaboradas por la jurisprudencia de la Rota Romana. Diferentes, en cierto sentido, de las presunciones son las máximas de experiencia; sobre lo cual, véanse: LABANDEIRA, E., Las máximas de experiencia en los procesos canónicos, en Ius canonicum, 29 (1989), pp. 261-267, a propósito del nexo entre máximas de experiencia y presunciones, que pueden ser utilizadas por el juez en sus decisiones. Sobre el argumento en general, OrTIZ, M. Á., Circa l'uso delle presunzioni nelle cause di nullità del matrimonio, en Ius Ecclesiae, 8 (1996), pp. 839-885. PALOMBi, R., Le presunzioni, en Bonnet, P.A. - Gullo, C. (editores), Il giudizio, cit. (n. 27), pp. 441-476.

${ }^{32}$ Lefebvre, Ch., Procedure, en Dictionnaire, cit. (n. 13), VII, coll. 281-309. Por ejemplo, algunos cánones de los concilios africanos del sec. V presentan reglas sobre los testigos. Sin duda, tiene una huella romana el can. De testium del concilio de Cartago del 30 mayo 419: "Testes autem ad testimonium non admitendos qui nec ad accusationem admitti praecepti sunt, vel etiam quos ipse accusator de sua domo produxerit. Ad testimonium autem intra XIV annos suae non admittantur" en Corpus Iuris Canonici, Editio lipsiensis secunda post Aemilii Ludouici Richteri curas ad librorum manu scriptorum et editionis romanae fidem recognouit et adnotatione critica instruxit 
Para tener un cuadro completo de la normativa de la prueba testifical es necesario considerar además de los artículos 193-202 de la Dignitas connubii (=DC.), el capítulo sobre el examen judicial (artículos 162-176) y las restantes disposiciones generales que resultan en los artículos 155-161, mayormente explicitadas y ampliadas respecto a las que encontramos en los cánones 1547ss.

Sobre la eficacia de la prueba testimonial y en concreto si a esta tuviese que darse la preferencia o no en relación a la prueba documental, se discutió desde tiempos lejanos, discusión que no tenía, bajo el imperio del Código del 1917, demasiado sentido para algunos autores, aún reconociendo la justificación en parte de dicha polémica dado que esta insistía en la mayor dificultad y en el mayor riesgo de error existente en la prueba testimonial en relación a la dificultad que podría encontrarse para constatar la autenticidad de un documento. La polémica vertía en efecto no sobre la eficacia de la prueba testifical en abstracto, sino sobre la valoración del resultado concreto para afirmar la exigencia de una mayor capacidad intuitiva y de una mayor dote de prudencia en la criba y en la interpretación de los testimonios.

El Código de Derecho Canónico vigente ha colocado este medio de prueba después de las declaraciones de las partes y de la prueba documental, porque los testimonios son una prueba más incierta en cuanto que el juez tiene que asegurarse que no haya sido producida con mala fe o con otros intereses que no la hagan atendible. En concreto, la materia del capítulo $3^{\circ}$ : De testibus et attestationibus del título $4^{\circ}$ : De probationibus comprende la identidad y credibilidad de los testigos, contenido de los testimonios, circunstancias relativas.

2. La prueba testimonial es aquella constituida en juicio por los testimonios dados en juicio por personas de reconocidas idóneas a ello por el derecho: testigo es, pues, una persona idónea y distinta de las partes litigantes, admitida por el juez a declarar de ciencia propia o de oídas en juicio sobre un hecho controvertido en orden al pronunciamiento del juez en la sentencia; el testimonio contribuye a alcanzar la necesaria certeza moral para una justa decisión.

Es ésta la prueba más compleja y que necesita mayor empeño y trabajo por parte del juez o del auditor.

El Código establece un principio en el canon 1547: la prueba testimonial está admitida en cualquier causa bajo la dirección del juez. Esta prueba queda

Aemilius Friedberg: Pars prior, Decretum Magistri Gratianii (Lipsiae 1879, ristampa: Graz 1959), C. 4, q. 2, c. 3: FriedberG I, col. 538. 
excluida ex materia sua del proceso documental para la declaración de nulidad de matrimonio, según los cánones.

Sub iudicis moderatione significa que se lleva a cabo según las modalidades indicadas por la ley, a las que debe atenerse el juez o el auditor, pero su fundamento es la presunción, en línea de principio, que el testigo llamado a deponer dirá la verdad sobre un hecho que es de su directo conocimiento (canon 1548); corresponderá después al juez asegurarse de que el testimonio dado haya sido sincero y objetivo y que no haya sido alterado por mala fe, pasiones, hastío o por cualquier otro interés hacia la parte.

La capacidad de testimoniar forma parte de los derechos de la persona, sin embargo, no será inútil recordar que omnespossunt esse testes, nisi expresse iure repellantur, vel in totum vel exparte (canon 1549; artículo 195 DC.). En efecto, aunque la obligación de testificar es una exigencia del bien público y de la vida social así como un deber de justicia, de esta obligación moral y jurídica el canon $1548 \$ 2$ presenta un doble motivo que exime de dicha obligación de responder como testigo: ratione officii-ratione damni. Ex ratione officii los clérigos relativamente a cuanto les ha sido confiado en razón del ministerio sagrado; los funcionarios civiles, médicos, abogados, notarios y todos aquellos que están obligados al secreto profesional o ex officio incluso en razón del consejo dado en todo lo que caiga bajo este secreto. Ex ratione damni quien teme infamia, peligrosas vejaciones o graves daños: a sí mismos, al cónyuge, a los consanguíneos o afines más directos y próximos.

Entre las disposiciones que impiden testimoniar se encuentran las expuestas en el canon $1550 \$ 2$, que trata de los testigos incapaces. Son aquellas personas que están implicadas en la misma causa, quienes han asistido o asisten a las partes. Se trata, además, de una incapacidad permanente a testificar. Por ello mismo, la Dignitas connubii aconseja que quienes puedan dar una contribución útil a la definición de la causa, y por tanto puedan ser llamados a testificar, no se impliquen en otro modo, no asuman obligaciones o cargos en la misma.

La norma del canon 1550 distingue, en efecto, dos categorías de personas que se excluyen como testigos: la primera no es absoluta, pues se deja al juez la oportunidad o menos de escucharlos si lo considerase necesario; la segunda, al contrario, es una norma taxativa y abraza a todos aquellos que por derecho son incapaces a deponer, ex eadem natura: algunos lo son ex iure ecclesiastico (canon $1550 \$ 2 \mathrm{n} .1$ ), otros ex iure divino (canon $1550 \$ 2$ n. 2). Así pues, en modo absoluto, quien tiene menos de 14 años, en parte, quien está obligado al secreto profesional. Los no admitidos a declarar y los incapaces ex iure (canon 1550) son dos categorías previstas en el Código de Derecho Canónico, mientras la categoría de los sospechosos y los no idóneos (menores y débiles mentales), considerada en el Código abrogado, ha sido 
suprimida, aunque sobre los no idóneos la norma deja a la prudencia del juez decidir sobre la necesidad o menos de admitirlos.

Las cualidades requeridas para ser testigo son tres: la ciencia directa de las cosas y personas; la honestidad de vida; la recta disposición a decir la verdad. A esta disposición se opone la colusión, que consiste en un pacto inicuo a daño de un tercero, entre testigo y una o ambas partes, sin necesidad de decir a toda costa el falso, y la sobornación, que es, al contrario, el influjo o la violencia moral sobre el testigo para inducirlo a testificar una cosa falsa.

3. Los testigos pueden ser presentados por las partes privadas o públicas, o bien, por iniciativa del juez, ex officio (cánones 1551-1557).

La prueba testifical comprende una fase preparatoria, es decir, el derecho de las partes a presentar testigos, la modalidad de presentación: número, petición formal, comunicación a las otras partes antes del interrogatorio. El momento procesal establecido por el derecho para la presentación de los testigos se coloca después de la contestación de la lite (pudiendo, sin embargo, indicar una eventual lista de testigos junto con la demanda inicial o libelo) y antes de la conclusión de la causa, teniendo en cuenta la prescripción del canon 1600. A la lista de testigos hay que añadir el cuestionario en base al cual interrogarlos, además de su dirección postal al fin de convocarlos en juicio.

Normalmente, la notificación de la lista de testigos debe hacerse antes de su interrogatorio, a no ser que la prudencia del juez, ante una verdadera dificultad, le impida actuar diversamente (canon 1554). En tal caso, la notificación tiene que tener lugar antes de que sean publicadas sus deposiciones judiciales, pero en esta hipótesis el derecho de exclusión de un testigo no podrá ser ya ejercitado.

En efecto, cada una de las partes, privadas y públicas, tiene el derecho de conocer los testigos presentados por la otra parte para poder ejercer el derecho de pedir su exclusión, motivada por una justa causa, demostrada y tiene que hacerse antes de la audición del testigo (canon 1555). La exclusión puede ser legal o procesal, que corresponde exclusivamente al juez, y en esto se diferencia de la reprobación de los testimonios, no contemplada en la nueva legislación canónica y que se colocaba en el momento procesal de la publicación de los testimonios al concluir el examen de los testigos y por ello antes de la conclusio in causa. La decisión del juez de aceptar una exclusión o de excluir un testigo tiene que ser motivada en in iure et in facto.

La reprobación del testigo consiste pues en la excepción propuesta por una de las partes contra un testigo para que no sea admitido a deponer judicialmente. Quien reprueba es el juez, el cual procede ex officio o a instancia de parte y en las causas que atienen al vínculo sagrado el defensor del vínculo tiene que ser oído antes. 
En caso de renuncia, a norma del canon 1551, ésta debe ser suficientemente justificada de manera que se elimine cualquier sospecha de interés contrario a la verdad. Debe ser aceptada y las partes pueden pedir que, de todas formas, el testigo al que una de las partes ha renunciado sea interrogado. Para la renuncia, el procedimiento es el mismo: la parte puede renunciar a un testigo, pero deben ser interpeladas las otras partes y, por tanto, el defensor del vínculo.

Cuando el número de testigos presentados es excesivo, el juez o el auditor tiene el derecho y el deber de disponer con un decreto los límites al número de los mismos (canon 1553) para que el proceso se lleve a cabo con la necesaria solicitud y sean evitados retrasos y gastos inútiles. Es una cuestión delicada, ya que es la parte que ha presentado los testigos quien realmente conoce la cualificación personal o respecto a la prueba de cada uno de ellos, por eso mismo el juez deberá invitar a la parte a reducir un eventual número excesivo de testigos siempre que ello no suponga para la misma parte ponerse en una situación de indefensión. Contra la decisión del juez, la parte interesada puede recurrir, y el juez está obligado a emitir un nuevo decreto expeditissime: aceptando o rechazando la petición expresada en el recurso.

A esta primera fase, sigue la citación de los testigos, como indicado en los cánones 1554-1557, que será notificada a quien corresponda en derecho. En fin, la última fase o interrogatorio de los testigos, previo juramento obligatorio en las causas atinentes al bien público.

\section{El EXAMEN DE LOS TESTIGOS}

1. Para garantizar al instructor (juez o auditor) la atmósfera necesaria para un examen sereno, atento, meditado, completo y exhaustivo de las cuestiones a tratar, para asegurar a las partes la posibilidad real de ilustrar las propias razones y argumentaciones, la ley canónica prevé un camino reglamentado de normas precisas, el proceso, que es como una vía cuyo eje es precisamente la búsqueda de la verdad objetiva y cuyo punto de llegada es la recta administración de la justicia ${ }^{33}$. De este camino forman parte las declaraciones de los testigos.

Se dice que el interrogatorio es legítimo si es realizado a dos condiciones: que sea llevado a cabo por el juez competente, y que se desarrolle en plena observancia del canon 1564.

El canon $1558 \$ 1$ dispone que los testigos deben ser interrogados en la sede del tribunal. La excepción a la norma sobre el lugar concierne a los

${ }^{33}$ Cfr. Paulo VI, "Alocución” a la Rota Romana, 28 enero 1978, en AAS., 70 (1978), p. 182. 
testigos de alta dignidad (cardenales, patriarcas, obispos y equiparados, quienes según el derecho de la propia nación gozan de este favor), y son ellos mismos quienes deciden el lugar donde ser interrogados. Sobre el lugar para el interrogatorio de los testigos que se encuentran por domicilio lejos de la sede del tribunal o quienes por enfermedad u otra razón justificada están impedidos, decide el juez; si el testigo se encuentra en territorio fuera de la competencia del juez, existen dos posibilidades: el exhorto (canon 1418), o bien, el traslado, es decir, el juez personalmente va en el territorio donde reside el testigo impedido siempre que exista una causa justa, oídas las partes y con licencia del obispo diocesano del lugar y en la sede que éste determine (canon $1469 \$ 2)^{34}$.

Cuanto a la modalidad de examen, los cánones 1560-1569 indican que el interrogatorio tiene que ser realizado individualmente, separadamente para que sean evitadas influencias negativas o preconstituidas que impidan después alcanzar la verdad y por tanto la certeza moral (canon $1560 \$ 1)^{35}$. Se trata de una medida de prudencia. Es más, las partes normalmente no pueden estar presentes al interrogatorio de los testigos, y esto con el fin de evitar de influenciarlos o turbarlos con su presencia (cánones 1559 y 1678). En las causas que no conciernen al bien público existe la posibilidad de derogar la norma, mientras que en las causas de nulidad matrimonial, la norma es menos severa. Los abogados y los procuradores, así mismo las partes públicas tienen

${ }^{34}$ José Luis López Zubillaga escribe en el comentario a esta norma: "el tiempo dirá si es acertada o no, pues parece que ha de encarecer notablemente el proceso y su razón de ser, dada la posibilidad de recurrir al auxilio judicial (c. 1418), no parece muy convincente", en Código de Derecho Canónico (ed. bilingüe comentada por los profesores de Derecho Canónico de la Universidad Pontificia de Salamanca, Madrid, BAC, 2008), pp. 840-841. Encarece seguramente el proceso, a cargo de las partes o del Tribunal, pero no hay duda, y es la experiencia personal que lleva a esta convicción, que un exhorto tiene limitaciones que, en comparación al coste del traslado del tribunal (a condición de que sea razonable en relación al número de personas que hayan de ser interrogadas y a la importancia de las mismas como testigos -lo que debería darse por descontado- y en relación a la sede donde se llevaría a cabo el interrogatorio), deberían tenerse bien en cuenta precisamente para evitarlo. El juez de exhortos no dispone de todas las actas recogidas precedentemente, por lo que se encontrará siempre limitado en la posibilidad de poner preguntas, de pedir aclaraciones, de contestar o replicar afirmaciones propuestas por otros testigos o por las partes, o bien, que resulten en documentos. Nos sentimos de poder afirmar que el exhorto no favorece plenamente a la finalidad del proceso, alarga la duración del mismo y entorpece, obviamente sin quererlo, la búsqueda de la verdad, es además un límite al principio de oralidad: quien debe juzgar debe establecer una relación procesal directa y personal con partes, testigos y peritos, mayormente en el proceso para la declaración de nulidad del matrimonio, que requiere ad validitatem, al menos en segunda instancia, un tribunal colegial.

${ }^{35}$ Cfr. Communicationes, 11 (1979), pp. 114-115, can. $204 \$ 1$. 
el derecho de asistir, a no ser que circunstancias particulares requieran que el testigo sea interrogado en secreto, o que el mismo testigo pida la ausencia de los abogados y, por tanto, del defensor del vínculo en la audiencia.

En el ámbito de estas normas se puede incluir la prohibición de comunicar las preguntas a los testigos antes del interrogatorio (canon $1565 \$ 1$ ), que tiene como finalidad la de evitar construcciones falsas de la verdad y la de obtener respuestas espontáneas y sinceras. En el caso en que se trate de cálculos, el $\mathrm{CIC}$ consiente el uso de apuntes previos e igualmente en el caso de hechos remotos en el tiempo el juez está autorizado a preanunciar algunos elementos que hagan recordar tales hechos al testigo (cánones $1565 \$ 2 ; 1566$ ).

2. Ante todo, el juez tiene el deber de recordar al testigo la obligación moral y jurídica de decir la verdad, incluso bajo juramento. Si una persona se negase a jurar, el juez tiene que recoger igualmente su testimonio, resultando en el verbal el rechazo a jurar y los motivos del mismo. Legítimamente llamado a deponer y legítimamente interrogado, el testigo tiene la obligación moral y jurídica de responder y de decir la verdad.

"Responsio sub ductu iudicis statim redigenda est scripto a notario et referre debet ipsa depositiones verba, saltem quod attinet ad ea quae iudicii materiam directe attingunt" ${ }^{\prime 36}$. Sólo el juez tiene la facultad de interrogar, es él quien propone y formula las preguntas a los testigos y quien dicta al notario o escribano. En esta fase, el juez tiene un papel de filtro, en cuanto responde ante Dios y ante su conciencia. El notario debe escribir bajo dictado del juez cuanto ha afirmado el testigo, aunque no con las mismas palabras, no obstante sería el ideal, pero el tipo de interrogatorio, que debería tender más a un coloquio que a pregunta-respuesta, hace más difícil el referir ipsissima verba del testigo.

El juez no debe limitarse a dictar las palabras pronunciadas en el interrogatorio, sino también eventuales circunstancias que acompañen a la deposición judicial o audiencia, por ejemplo la seguridad en las afirmaciones de los hechos, la incertidumbre, memoria lábil, excesiva emoción, apuros, turbación, etc. Puede proponer también preguntas ex officio ${ }^{37}$, con miras a

${ }^{36}$ Cfr. canon $1567 \S 1 ; D C$, artículo $173 \$ 1$.

${ }^{37}$ Se lee en el comentario de López Zubillaga al canon 1560 que "la ausencia del defensor del vínculo en las declaraciones de las partes y testigos lleva a veces a que sea el propio instructor quien, mediante preguntas de oficio planteadas por él mismo, intente resolver aquellos puntos obscuros de la causa, colocando sobre sus hombros una carga que se aviene mejor con la función de parte de los ministros públicos”, en Código de Derecho Canónico, cit. (n. 34). Se ha insistido mucho en estas páginas sobre la verdad y sobre cómo todos los que intervienen en el proceso estén obligados a su búsqueda y a sacarla a la luz; no se ve porqué debería suponer una carga para el instructor trabajar a 
esclarecer y profundizar las respuestas del testigo, facultad ésta que está en función de una instrucción del proceso completa y equilibrada, evitando al mismo tiempo excesivos prolongamientos del proceso y previniendo, pues, costosos y fatigosos suplementos de instrucción para completar lo que no ha sido bien hecho desde el inicio.

Es posible usar medios como el magnetófono -no medios telemáticos o el teléfono-, pero es necesario que la declaración sea después transcrita cuidadosamente y firmada por los asistentes a la audiencia, después de haber dado al testigo la posibilidad de escuchar el verbal y de leerlo, concediéndole la facultad de añadir, modificar o corregir lo que no considere oportuno (canon $1576 \$ 2$ ).

El verbal se estructura en las siguientes partes: la introducción en la que debe resultar el nombre del juez, de las personas que intervienen en la audiencia, la fecha, el lugar y la hora; la identidad del testigo, práctica religiosa y juramento. El cuerpo del verbal comprende las preguntas y respuestas. Las conclusiones: una vez leído el verbal para obtener la confirmación de que cuanto reportado en el verbal corresponde integralmente al pensamiento manifestado y expresado oralmente en el interrogatorio, el testigo puede aportar eventuales modificaciones, añadidos, etc. (canon $1569 \S 1)$. De la lectura del verbal no se debería dispensar, ni siquiera cuando el testigo afirma de haber seguido atentamente la verbalización del mismo, porque la experiencia enseña que volver sobre el mismo consiente no solo de corregir expresiones no precisas o correctas gramaticalmente, sino de añadir, aclarar o puntualizar.

El testigo puede ser sometido a examen antes de la publicación de las actas, e incluso después, a norma del can. 1600, si fuera necesario, pero a condición de que no haya peligro de colusión o corrupción, fraude, a petición de las partes o ex officio.

Si el juez lo considerase oportuno y necesario puede permitir la confrontación o cotejo entre los testigos, pero se trata de una modalidad excepcional para aclarar discordancias entre los testigos o entre estos y las partes, y siempre que no haya peligro de escándalo, disensiones o discordias (canon $1560 \$ 2)$.

3. Es una costumbre romano-canónica que la recogida de las pruebas no se lleve a cabo por el juez titular sino por otros, costumbre que deploraba no

favor del esclarecimiento de puntos obscuros o de colmar lagunas a través de preguntas de oficio. En muchos tribunales es, además, imposible materialmente que el defensor del vínculo participe personalmente asistiendo a cada uno de los interrogatorios, a motivo de la coincidencia de audiencias o simplemente a causa del excesivo número de causas de las que es titular como tutor del vínculo. 
obstante el Hostienses: "judices per se raro recipiunt testes, vel eos examinant, sed illa committunt aliis" 38 , y que aún hoy abunda no poco en nuestros tribunales a través de la figura del auditor o del juez de otra jurisdicción (exhorto); el recurso a estas figuras - propio de un proceso escrito en el que tiene amplia cabida el principio de mediación- hace más bien discontinua y defectuosa la instrucción, además de prolongar los tiempos de la misma. Al contrario, se tiene poco en cuenta la posibilidad de que el tribunal se traslade al domicilio de la persona que debe ser interrogad $a^{39}$, particularidad que mantiene vivo -aunque parcialmente, por la razones ya aducidas anteriormente- el principio de la inmediación ${ }^{40}$.

Volviendo sobre la modalidad del examen de los testigos, el artículo $171 D C$., retomando el can. 1560, señala un principio de carácter general: interrogandi oretenus respondeant.

El desarrollo oral del interrogatorio es, ciertamente, la forma más idónea para proporcionar al juez un cuadro seguro de los hechos relevantes al fin de una decisión y por tanto de una sentencia justa. Sobre todo escuchando y mirando hablar a la persona interrogada o examinada y dialogando con ella es posible hacerse una idea más precisa de cuanto en verdad ella pretenda expresar, si está convencida de decir la verdad, de controlar si incurra en errores de percepción, de fijación de recuerdos o de evocación, o bien, si dice intencionadamente el falso ${ }^{41}$, a pesar de la grave obligación de decir la verdad ${ }^{42}$. La oralidad es importante, pues, para que el juez obtenga una valoración aproximativa de la personalidad del sujeto y para determinar su

${ }^{38}$ Summae Hostiensis (Venetiis 1581, ristampa Torino, 1965), lib. I: De off. iud. Justiniano había advertido también la misma necesidad de tratar las controversias desde el inicio hasta su fin por parte de los jueces, para que mediante la inmediación fuese administrada una recta justicia, cfr. Corpus Iuris Civilis, cit. (n. 11), Novellae Const., LX, cap. 2.

${ }^{39}$ Cfr. canon $1469 \$ 2 ; D C$., artículo $85 \$ 2$.

${ }^{40}$ No podemos prescindir, en este apartado sobre la valoración de la prueba testimonial en vista de la formación de la certeza moral en el juez, del principio de oralidad y escritura en el proceso canónico que encontramos igualmente presente en la Dignitas connubii; sobre el particular, reenviamos al nuestro estudio publicado en esta misma revista, Hernández Rodríguez, M. V., Los principios generales de oralidad y escritura en el proceso canónico según la instrucción Dignitas connubii, en Revista de Derecho de la Pontificia Universidad Católica de Valparaíso, 34 (Valparaíso, Chile, 1er semestre de 2010), pp. 637-663.

${ }^{41}$ Cfr. Malinverni, A., Oralità, II, en Enciclopedia giuridica (Treccani, Roma, 1990), XXI, pp. 2-3. En relación a la mentira y a la sinceridad, a la falsedad y a la verdad, véase Battistelli, L., La bugia (Laterza, Bari, 1923); Carponi Schitar, D., La menzogna nel processo: no dire false testimonianze (Milano, Giuffrè, 2004).

${ }^{42}$ Cfr. canon 1532; canon $1562 \$ 1-2 ; D C$., artículo $167 \$ \$ 1-3$. 
credibilidad sobre el testimonio ${ }^{43}$, por eso estas observaciones particulares sobre la persona interrogada o sobre hechos concretos acontecidos en el curso del interrogatorio se deberían unir -siempre que sea respetado el principio de la caridad y de la prudencia- al verbal de la audiencia con el fin de iluminar al Colegio en su decisión, dado que no todos los miembros del mismo han tenido acceso a una relación directa y personal con los testigos y sobre todo cuando es un auditor (canon $1428 \$ 2$ ) quien recoge las pruebas testificales ${ }^{44}$.

El artículo $169 D C$. -expresión idéntica del canon 1564- recuerda las características que deben tener las preguntas propuestas al testigo: "breves, interrogandi captui accommodatae, non captiosae, non suggerentes, non subdolae, remotae a cuiusvis offensione, pertinentes".

$\mathrm{El}$ interrogatorio consiste en una serie de preguntas dirigidas a alguien para obtener información o explicaciones, aclaraciones sobre algunos hechos. La parte que dirige la pregunta, y por tanto el interrogatorio, está investida de una autoridad y superioridad que da un tono investigador al acto, y que puede por ello mismo producir reacciones y estímulos en el interrogado. Sin embargo, no obstante esta situación objetiva, el juez o el auditor en las causas de nulidad matrimonial tiene que estar dotado de actitudes y cualidades que hagan de la recogida de la prueba testifical -y lo mismo se podría decir y con mayor razón de las declaraciones de las partes- no un interrogatorio

43 “Ovviamente, poiché l'interrogatorio della parte, così come la testimonianza, è un atto di coscienza, conoscenza e volontà essa è un tipico atto giuridico, che -come tutti gli atti giuridici- presuppone che la parte sia capace di intendere e di volere, abbia coscienza di ciò che ha fatto, di ciò che ha percepito e di ciò che dice. Se, dalla documentazione prodotta in atti, è evidente che la parte (o il teste) (can. $1550 \$ 1$; art. $196 \$ 1$ Inst. "Dignitas Connubii") è incapace di intendere e di volere [...] è inutile interrogarla a meno che qualcuna delle parti pubbliche o private metta in discussione questa sua capacità e ritenga sia necessario verificarla. In ogni caso, è da respingere, perché non ammessa dalla legge, la prassi di questi Tribunali che si limitano a recepire gli affidavit delle parti (e anche dei testi) senza procedere al loro formale interrogatorio e senza fare alcuna contestazione", en Gullo, C. - Gullo, A., Prassi processuale nelle cause canoniche di nullità del matrimonio ${ }^{2}$ (Città del Vaticano, Libreria Editrice Vaticana, 2005), p. 162.

${ }^{44}$ Estos hechos dignos de mención, para los que se reenvía al art. $174 D C$., van al final del verbal, después de las firmas de quienes han asistido al interrogatorio. No están exentas de riesgos a causa de un posible excesivo subjetivismo por parte del instructor o del notario, por ello deben hacerse con moderación y prudencia a fin de evitar un injusto condicionamiento a los jueces sobre la valoración de las pruebas. En fase de reforma del Código, fue rechazada por dos veces la propuesta de relación del juez instructor sobre elementos o circunstancias sobresalientes durante la audición de las partes o de los testigos porque "animi aliorum iudicum pertractari possent a considerationibus forte subiectionis", en Communicationes, 11 (1979), p. 117; 38 (2006), p. 258. 
en sentido estricto, sino un momento de encuentro con la Iglesia. Tiene que ser consciente que aun mostrando cercanía y humanidad su papel, su rol actúa en un modo o en otro sobre el interrogado, que reacciona en manera consciente o inconsciente, corriendo el riesgo de alterar sus declaraciones. Mayormente en las personas emotivas, fáciles a la sugestión. Es por ello que, como decíamos, el interrogatorio tiene que adquirir el carácter de coloquio, de conversación, de diálogo, de modo que se provoque una declaración espontánea, más fiel que el mero interrogatorio. No nos parece que sea más incompleto el testimonio a condición de que vaya dirigido por el juez, haciendo hincapié sobre hechos importantes. Ciertamente se corre el riesgo de informaciones superfluas y conlleva mayor empleo de tiempo.

A veces el testigo se encuentra en la dificultad a expresarse ante un juez que por carácter o por imprudencia crea sujeción, o que se limita a preguntarespuesta, impidiendo quizás al testigo ir más allá de cuanto formulado expresamente en la pregunta. Un interrogatorio a base de pregunta-respuesta, sin que haya espacio a un diálogo, a un coloquio entre el testigo y el juez difícilmente pondrá en luz la complejidad del comportamiento humano, las motivaciones profundas que han llevado a las partes a actuar en una dirección determinada. Ciertamente, tiene también sus riesgos, pues el juez deberá prestar suma atención a no provocar en el testigo una respuesta no conforme a la verdad de los hechos, a no dejar traslucir una información que pueda suscitar en el testigo una determinada respuesta. La respuesta del testigo debe provocar por lo general otras preguntas o intervenciones del juez encaminadas a aclarar, profundizar, etc.; la experiencia enseña que muchas veces los testigos no resultan informados o escasos en sus deposiciones porque no se les ha preguntado suficientemente o porque no se les ha dejado expresar completamente, dando lugar a deposiciones en algunos casos aparentemente contradictorias: "nadie me preguntó sobre esto o aquello", es una expresión que se repite en casos símiles.

En conclusión, sea a las partes que a los testigos es necesario asegurarles un ambiente sereno y atento, de modo que puedan ilustrar en manera completa las propias razones, evitando así de banalizar la vida de las partes en un interrogatorio veloz, muchas veces con la excusa de no someterlas a un, erróneamente considerado, tormento. Para muchas personas, creyentes o no, más o menos practicantes desde el punto de vista religioso, la declaración -en cualidad de parte o de testigo- ante el juez es, en muchas ocasiones, ocasión una confesión en sentido amplio, una sesión terapéutica, un desahogo, una posibilidad de clarificación de la propia vida y del propio comportamiento que debería encontrar en el instructor esa acogida y esa respuesta que explicite, como ninguna otra parte del proceso, el sentido y la finalidad pastoral del mismo. 
4. No es raro que en el proceso puedan intervenir personas que no conocen la lengua oficial: en estos casos, cuando dichas personas tengan que prestar declaraciones orales en el proceso y el juez no conozca la lengua hablada por las mismas, se tiene que recurrir a la obra de un intérprete ${ }^{45}$, el cual, antes de ejercitar sus funciones, presta juramento ante el juez de cumplir fielmente su oficio y de observar el secreto. Y de esta posibilidad del intérprete -considerado que hoy la diversidad lingüística se ha convertido en una realidad presente en cualquier país y de consecuencia en nuestros tribunales- no se debería prescindir cuando se prevean eventuales dificultades de entendimiento y de comprensión en el curso del interrogatorio, a motivo del insuficiente conocimiento de la lengua oficial por parte del interrogado o examinado.

Si en el procedimiento tiene que ser interrogado un sordo, un mudo o un sordomudo, las preguntas y las respuestas pueden hacerse por escrito y con la ayuda incluso de un intérprete especialista con el objeto de hacer del interrogatorio una normal conversación y un coloquio vivo.

\section{El VAlor de los testimonios}

La valoración de las pruebas constituye el trabajo más delicado e importante del juez, que debe examinar atentamente las pruebas testimoniales recogidas y juzgar la credibilidad de las mismas y su fuerza probatoria con alto sentido de responsabilidad. Esto exige algunas cautelas.

Cuanto a la valoración de las pruebas, los sistemas jurídicos oscilan entre dos extremos: o remiten la valoración de las pruebas al juez o imponen reglas más o menos rígidas que el juez tiene que seguir en dicha valoración. El espíritu profundo de la tradición romana era favorable a la libre apreciación de las pruebas aunque el derecho postclásico y justinianeo comenzó a dar un cierto número de reglas al juez. La tradición romana conservaba el respeto a una cierta libertad del juez, pero de hecho no ha faltado nunca de darle normas en la valoración de los testimonios; en el curso de los años, sin embargo, se ha inclinado siempre más hacia la afirmación de la libertad del juez, como se evidencia en la legislación vigente y como hemos tenido ocasión de insistir precedentemente.

Interpretar a un testigo y sobre todo interpretarlo correctamente, entrando en su personal psicología -en relación a la índole, profesión, cultura, momento judicial- no es siempre fácil: es necesaria mucha clarividencia y prudencia para establecer el fundamento objetivo de sus afirmaciones.

El canon 1572 (cfr. canon 1789 CDC. 1917) retoma las directivas del Código abrogado en materia de testimonios: el juez, en la valoración de los

${ }^{45}$ Cfr. DC., artículo 172; canon 1471. 
testimonios, tiene que tener en consideración la condición y la honestidad de la persona-testigo; si el testimonio es por conocimiento personal, sobre todo si ha visto y oído personalmente, es decir, de scientia directa, o bien, en base a la propia opinión, por fama o haberlo oído a otros; si el testigo sea constante y coherente consigo mismo, o al contrario, contradictorio, inseguro o dudoso, y en relación a cuanto ha sido depuesto por otros testigos.

Los primeros elementos de valoración son elementos subjetivos, referentes a la persona que testifica: podemos subrayar los hábitos de cultura y de profesión que facilitan muchas veces la percepción, la observación, la fijación del recuerdo, la libertad de expresión, la exposición ordenada y clara; en efecto, es posible apreciar todo ello en las declaraciones, atendiendo con diligencia a las narraciones que de los hechos hace el testigo, culto o inculto, perteneciente a tal o cual profesión, sobre todo si ésta se halla íntimamente relacionada con el asunto que se presenta y se narra; a las dificultades o temores en personas de condición humilde y sencilla; a la mejor comprensión y expresión del testigo culto, a condición de que sea veraz; a las tendencias mentales del mismo: si es persona receptiva y observadora, creadora e interpretadora, divagadora, poco equilibrada (alguna perturbación sin que se llegue a retrasados mentales u otro), desmemoriada (sobre todo en relación a fechas o cronología de los hechos), exagerados, o aquellos que conservan recuerdos no fieles sino deformados por el tiempo, el olvido, la elaboración posterior de los hechos en base a reflexiones personales o a confidencias o informaciones recibidas sucesivamente; a las disposiciones afectivas: el influjo del corazón, los sentimientos, los afectos comportan o producen deposiciones parciales, aunque a veces algunas manifestaciones pueden ser señal de veracidad de cuanto se afirma.

2. Los elementos formales de la valoración se refieren a la forma observada en la práctica del examen y al acta judicial levantada.

Es importante conocer la razón de la parte en la propuesta del testigo: saber quién le propuso como testigo y porqué. La presentación es tanto más sospechosa cuanto más tardía y extemporánea sea, por ejemplo después de la publicación de los autos, después de la conclusio in causa, aún más sospechoso si fue presentado en segunda o sucesiva instancia, siendo quizá un familiar de la parte; no es tampoco raro el caso en que viene indicado como teste un hermano de la parte que al momento de los hechos tenía pocos años de edad, mientras que no se indica ninguno de los hermanos mayores; viceversa, es interesante también llamar como testigo de oficio a aquella persona que ya desde el inicio del proceso la parte pide que no sea convocada por los clásicos motivos de edad o salud (como hemos visto, existen diferentes vías para poder recoger la deposición judicial de un testigo sin necesidad 
de incomodarlo indebidamente). En la instancia de presentación, se deben indicar las razones y se deben escuchar a las otras partes en relación a la presentación del testigo.

Interesante en la valoración de la prueba testifical es la consideración de los testigos llamados de complacencia: familiares, amigos a los que después del fracaso matrimonial se cuentan los hechos o en vista de la introducción de la causa, conviviente o nuevo partner en sede civil. Es un relato bajo la influencia de una situación concreta, y por eso mismo se revela como parcial, incompleto y deformado algunas veces. No está de más recordar la necesidad de averiguar siempre cuándo, por dónde y de qué modo el testigo ha sabido las cosas que expone y si, en la exposición, afirma o son suposiciones personales y en base a cuáles hechos apoya tales afirmaciones o suposiciones.

No hay duda de que el testimonio de una persona mente debilis tenga escaso valor de prueba, y lo mismo podría decirse del niño o adolescente, pero en relación a éste hay que precisar que, con tal de que al momento al que se refiere su testimonio fuese capaz de percibir el hecho atestado, aunque no fuese en grado de valorarlo bien, su deposición no quedará pues destituida de valor; además, el juicio que él, gracias a la capacidad adquirida posteriormente, habrá podido hacer sobre el hecho percibido precedentemente, como simple visión del mismo, integrará su testimonio al punto de darle utilidad en el proceso (interesante sobre este punto una coram Florczak, 29 iunii 1923, dec. XIV n. 9; 21 ianuarii 1924, dec. III, n. 6).

El modo de expresarse y de hacer el relato es uno de los elementos formales de valoración al que hay que prestar atención diligente.

El recuerdo excesivamente preciso y uniforme (normalmente no es natural), insistiendo sin razones y sin que haya sido interpelado directamente sobre cuestiones de carácter estrictamente jurídico (insistir denodadamente en el término divorzio sin ofrecer razones remotas ni próximas) como son los requisitos de prueba. En casos de testigos preconstituidos o no, la valoración es obviamente diferente y las expresiones también, tanto que preguntando de más al primero quizá no sepa responder, o bien, siendo una persona poco culta, se exprese, sin embargo, con términos jurídicos como puede acontecer en relación al capítulo de nulidad ex can. $1097 \S 2$ : "la parte buscaba directamente y principalmente tal o cual cualidad en la otra parte [...]".

Ocurre a veces que en segunda instancia la expresión de primer grado era deficiente sin culpa del testigo, o bien, excesivamente precisa, porque la verbalización no correspondía a cuanto expresado por el testigo sino que se era cosecha del instructor. Así, pueden resultar instrucciones enteras en las que se observa cómo las deposiciones de los testigos son copias, a veces incluso literales, unas de otras. Sin culpa del testigo, porque probablemente no fue profundizado o aclarado suficientemente su relato. En caso de in- 
terrogatorios reiterados es efectivamente necesario individualizar si existe coherencia o contradicciones.

En tema de uniformidad de testimonios, conviene indudablemente descubrir posibles causas de tal uniformidad: sospecha de preparación de los testigos; omisión de verbalizar en autos las preguntas hechas; el conjunto de los testimonios confrontados.

La falta de uniformidad, coherencia, firmeza, que si existen indudablemente valorizan, bajo el aspecto objetivo, la deposición judicial, dependerá de la actitud, a favor, en contra o de neutralidad que el testigo habrá asumido en relación a la causa, pero también podrá depender de la psicología del testigo, es decir, sobre sus condiciones personales propias, especialmente la inteligencia, carácter, cultura que influirán más o menos $^{46}$. Por este motivo, sería peligroso que el juez, en la valoración de la prueba, tomase en consideración solamente la cualidad de la deposición para determinar la credibilidad del testigo, así como se equivocaría si considerase solamente las cualidades personales del testigo para establecer el valor de prueba de una deposición.

Ciertamente, el juez, en la valoración de los testimonios deberá captar lo esencial en la variedad, en otras palabras, no puede pretender una coincidencia o uniformidad plena en cosas secundarias, porque esto en vez de argüir credibilidad indica verosimilitud. Sin embargo, la coherencia interna se presenta como un requisito de credibilidad del testimonio.

3. La jurisprudencia rotal ha elaborado criterios de valoración de la prueba testifical $^{47}$.

El número de testigos no debe ser valorado en exceso: es necesario, sin embargo, que los testigos sean dignos de crédito, en primer lugar, y en se-

${ }^{46}$ Coram Lega, diei 17 ianuarii 1912, ARRT. IV, dec. V, n. 10.

${ }^{47}$ Cuanto a la autoridad de la jurisprudencia (in iure) de la Rota Romana y en modo particular sobre aquella atinente a las declaraciones de nulidad del matrimonio, se puede consultar: Montini, G. P., L'unità della giurisprudenza: Segnatura Apostolica e Rota Romana, en Gruppo Docenti di DiritTo Canonico (editor), I giudizi nella Chiesa: il processo contenzioso e il processo matrimoniale (Milano, Quaderni della Mendola, 1998), pp. 219-244; Jullien, A. Card., Juges et Avocats des Tribunaux de l'Église (Roma, 1970); Fransen, G., La valeur de la jurisprudence en droit canonique, en La norma en el Derecho canónico (Pamplona, 1979), I, pp. 197-212; PoMPEDDA, M. F., La giurisprudenza come fonte di diritto nell'ordinamento canonico matrimoniale, en 2 uaderni di Studio Rotale, 1 (1987), pp. 47-72; PALEARI, E., Considerazioni sul carattere creativo della giurisprudenza canonica in tema di nullità matrimoniale (Urbino, 1979). Sobre la actividad jurisdiccional de la Rota Romana y sobre el valor de la misma, se vean los discursos y alocuciones de los Pontífices en ocasión de la inauguración de los años judiciales, publicados en Acta Apostolicae Sedis: Paulo VI, 28 enero 1972; 31 enero 1974; Juan Pablo II, 24 enero 1981; 28 enero 1982; 26 enero 1984; 30 enero 1986. 
gundo, que sean de scientia directa. A veces pocos testigos son suficientes si sus testimonios contienen los elementos necesarios para cubrir los requisitos de prueba.

Así mismo, entre los testigos presentados por las partes públicas o privadas o ex officio, no pueden faltar aquellos que hayan tenido que ver directamente con el aspecto central de la causa; en otras palabras, en una causa concerniente al capítulo de nulidad ex can. 1103 no puede faltar el autor del metus o metus incutiens, o al menos quien directamente ha presenciado el ejercicio de presiones, amenazas, etc. sobre el metus patiens. Testigos de suma importancia en este capítulo de nulidad son "propinqui et familiares qui arctiore vitae consuetudine cum metum patiente gaudent"; en efecto, "quae inter domesticos parietes evenerunt, familiares praesumuntur novisse plenius quam extranei" 48 .

Con referencia a este capítulo de nulidad ex metus reverentialis, la Rota Romana ha hecho suyo la máxima que desde las Decretales afirma que " $m a$ gis credendum est duobus testius qui coactionem et metum confirmant, quam mille negantibus" 49 .

En la prueba de la incapacidad ex can. $1095 \mathrm{nn} .2-3$, no puede por ejemplo pasarse por alto, entre los testigos, al sacerdote que asistió a la boda, hermano de una de las partes y además, de hecho, tutor de la misma; o al sacerdote párroco que, conociendo bien a las partes, se negaba de asistir a la celebración del matrimonio porque no consideraba una de ellas compos sui. Los testigos van seleccionados, no elegidos o llamados al azar.

En tema de descripción de la personalidad y del carácter de los cónyuges por parte de los testigos, éstos tienen que referir la verdad sobre hechos vistos, según su experiencia empírica común, mientras que al perito corresponde dar a esos hechos y descripciones de la personalidad una interpretación científica, según la ciencia pisco-clínica ${ }^{50}$.

No es necesario que todos los testigos refieran unánimemente las mismas circunstancias, los mismos episodios porque las deposiciones hay que considerarlas "potius quam ex singulis assertis ex toto complexu". Viceversa, una evidente conformidad y semejanza podría crear sospecha "testes ab actore inducti similiter ac Actor, non videntur fidem mereri, cum eorum depositiones una voce sonant, iisdem verbis utentes" ${ }^{\text {. }}$.

${ }^{48}$ Coram Defilippi, diei 16 februarii 1995, ARRT. Dec., LXXXVII, p. 127, n. 11.

${ }^{49}$ Coram Corso, diei 30 maii 1990, ARRT. Dec., LXXXII, p. 399, n. 10; coram Davino, diei 18 maii 1989, ARRT. Dec., LXXXI, p. 369, n. 12. En esta sentencia última es posible consultar ulteriores indicaciones sobre el argumento.

${ }^{50}$ Coram Colagiovanni, diei 16 novembris 1993, ARRT. Dec., LXXXV, p. 658, n. 25; coram Stanchiewicz, diei 17 dicembris 1993, ARRT. Dec., LXXXV, p. 802, n. 12.

${ }^{51}$ Coram Palestro, diei 26 maii 1993, ARRT. Dec., LXXXV, pp. 415-146, n. 4. 
Una atención particular merecen los testigos de tempore suspecto, es decir, que han sabido o recibido confidencias de las partes cuando la causa estaba ya introducida; "in iurisprudentia constanter servatur principium, quo priores depositiones tamquam veritati magis consonae, successivis praevalent" 52 .

No pocas veces ocurre que, sobre todo en segunda instancia, un testigo interrogado nuevamente difiera respecto a la deposición ofrecida en primera instancia. Lagunas, imprecisiones, incluso contradicciones van aclaradas y sobre todo va verificado el motivo: "aliud est magis definire et accurate easdem res pedetemtim referre; aliud autem contrarias postea dicere quam antea, pero si ea quae prius negavit vel saltem ignorare dixerit, nunc palam affirmat, tunc difficulter ei credit potest". La misma sentencia establece una presunción en este caso: la primera deposición prevalece sobre las siguientes ${ }^{53}$. Se lee a propósito en una famosa decisión coram Grazioli: “...si hoc detur, docent auctores standum esse primae testis depositioni, iuxta arg. cap. Per tuas, 10, de probat. Praesumitur enim... testem in prima depositione et melius factgus meminisse et locutum fuisse iuxta persuasionem animi sui..." 54 .

De todas formas, un semejante criterio puede parecer demasiado formalístico y si el testis varius no puede no crear sospecha en el juez, es necesario, sin embargo, distinguir siempre si la inconstancia recaiga sobre un hecho importante o sobre una circunstancia accesoria, para evitar que el testimonio más digno de crédito no se convierta en el más falso, pretendiendo además que las cualidades de la memoria puedan ser iguales en todas las personas, en todo momento y en orden a cualquier serie de hechos. A menudo, en efecto, lo que parece contradictorio no es, en realidad, que una explicación más exacta, una mayor determinación del hecho.

No es irrelevante el hecho frecuente de ver a los testigos alienados junto a la respectiva parte que los ha presentado y contrarios a la otra ${ }^{55}$ : el primer elemento que hay que considerar es la coherencia inter dicta et facta. El segundo es conocer si hay alguna razón grave que haya llevado a la parte a oponerse a la causa ${ }^{56}$.

4. En cuanto al testis unus, testis nullus ${ }^{57}$, il canon 1791 del Código de

${ }^{52}$ Coram Pinto, diei 17 ianuarii 1997, ARRT. Dec., LXXXVIII, p. 37, n. 13.

${ }^{53}$ Coram Defilippi, diei 18 decembris 1996, ARRT. Dec., LXXXVII, p. 824, n. 10.

${ }^{54}$ Coram Grazioli, diei 2 iulii 1924, ARRT. Dec., XVI, dec. XXII, n. 21.

${ }^{55}$ Coram Pompedda, diei 13 iulii 1987, inédita; coram Funghini, diei 18 decembris 1991, ARRT. Dec., LXXXIII, p. 848, n. 5.

${ }^{56}$ Coram Funghini, diei 18 decembris 1991, ARRT. Dec., LXXXIII, p. 848, n. 5.

57 "Non enim ad multitudinem respici oportet -afirmaba Arcadio- sed ad sinceram testimoniorum fidem et testimonia, quibus potius lux veritatis adsistit" (D. 1.21, 53; 22, 
Derecho Canónico de 1917 presentaba fielmente las dos reglas basilares concernientes al valor de la prueba testimonial en el derecho de las Decretales; la deposición de un testigo no puede constituir prueba plena a no ser que se trate de un testigo cualificado que deponga sobre cosas de oficio; si bajo el vínculo del juramento, dos o tres personas omni exceptione maiores coherentes consigo mismas testimonian sobre una cosa o un hecho de tiempo no sospechoso, se tiene una prueba suficiente, a no ser que indicios o dudas serias sugieran el contrario.

El antiguo axioma, de claro sabor formalístico y legalístico en su formulación, ha sido de hecho suprimido en virtud de la jurisprudencia precedente al 1983 y atenuado en la norma positiva en el nuevo Código en el canon 1573. En efecto, la vigente norma canónica prevé que el testimonio de un solo testigo pueda constituir una prueba plena cuando rerum et personarum adiuncta den absoluta prueba de credibilidad al mismo testigo. La jurisprudencia rotal ha afirmado en muchas ocasiones que el principio tiene que ser interpretado en modo menos rígido y formal. Se lee en una coram Felici que la regla del canon 1791 del Código abrogado no tiene que ser interpretada de modo que si no existen dos testigos de ciencia directa no se podrá nunca probar una afirmación o un hecho con otros argumentos. De lo contrario, se coarta excesivamente la libertad del juez en la valoración de las pruebas.

Este principio ha sido seguido por la antigua y restaurada Rota ${ }^{58}$ : "Unum testem exceptione maiorem et de scientia, cuius depositio univoce ceterisprobationibus roboretur, aliquando sufficere non raro affirmavit Nostrum Apostolicum Tribunal (cf. coram Prior, diei 13 maii 1921: ARRT. Dec., vol. XIII, p. 105, n. 7; coram Chimenti, Transilvanien., diei 5 iulii 1921: ibid., p. 157, n. 2; coram Mattioli, Versalien., diei 7 novembris 1951: ibid, vol. XLIII, p. 689,

5). Dos testigos era considerado suficiente según el ius romanum, refiere en propósito Ulpiano: "Ubi numerus testium non adicitur, etiam duo sufficient: pluralis enim locutio duorum numero contenta est" (D. 1.37 ad edictum, 22, 12). Sobre el principio unus testis nullus testis el derecho romano concordaba con las Sagradas Escrituras (Mt 18, 16: In ore duorum vel trium testium stat omne verbum; Dt. 19, 15; X, 2, 20, 23, Friedberg, II; 323): el principio se encontraba también en el Corpus Iuris Civilis (C. 1, 4, 20, 8; D. 48, 18, 20 - Paolo). Boccalini, T., De unico teste in iure canonico, en Fedele, P. (editor), Studi di diritto canonico in onore di M. Magliocchetti (Roma, 1974), I, pp. 203-234; De Lanversin, B., Valeur d'un témoignage unique an procès, en L'année canonique, 12 (1968), pp. 364-365. FERNÁNDEZ EsPINAR, R., El principio “testis unus testis nullus" en el Derecho procesal español (Madrid, 1979).

${ }^{58}$ Cfr. coram Rossetti, diei 6 iunii 1918: ARRT. Dec., X, p. 45, n. 7; coram Chimenti, Transilvanien., diei 5 iulii 1921: ibíd., XIII, p. 157, n. 2; coram Prior, diei 12 novembris 1921: ibíd., p. 265, n. 4; coram Prior, diei 31 martii 1922: ibíd., XIV, p. 88, n. 8; coram Chimenti, diei 23 novembris 1923: ibíd., XV, p. 285, n. 11; coram Massimi, diei 21 decembris 1923: ibíd., p. 317, n. 12. 
n. 2; coram Mattioli, Salutiarum, diei 18 iulii 1956: ibid., vol. XLVIII, $p$. 686, n. 2; coram Ewers, Vic. Apost. Laen., diei 18 ianuarii 1969: ibid., vol. LXI, p. 36, n. 3; coram Abbo, Cliftonien., diei 6 februarii 1969: ibid., p. 140, nn. 7-8; coram Huot, Tokien., diei 1 februarii 1973: n. 4 (inédita); coram Serrano, Tokien., diei 18 aprilis 1975: ARRT. Dec., vol. LXVII, p. 327, nn. 6-9; coram Masala, Tokien., diei 27 ianuarii 1977: ibid., vol. LXIX, p. 34, n. 15; coram Parisella, Romana, diei 11 ianuarii 1979: ibid., vol. LXXI, p. 3, n. 5)" 59 .

"Eadem usque in praesens vigere - se lee en una recordada sentencia coram Serrano del 18 de abril de 1975-demonstratur ex decisione quadam S. T. Signaturae Apostolicae, publici iuris facta (cf. Periodica de re morali, canonica, liturgica, vol. 64 [1975], fasc. 1-2, pp. 205-208), ubi S. Tribunal absque processu declaravit nullitatem cuiusdam rnatrimonii ad quam evincendam unus tantum erat testis ex auditu, magna credibilitate praeditus" ${ }^{60}$. En realidad "exiguitas vel paucitas testium simpliciter et sua vi considerata signum non est levitatis et fragilitatis thesis actoreae: eo vel minus prorsus negativum indicium secumfert adversumque iudicium urget. Aliquando illa enim uni utriusque coniugis reconditae naturae est tribuenda cum hi amicitias haud foverint atque suorum consiliorum participes ac secretorum omnium arbitros excluserint, aliquando nimio transacto tempori a celebratis nuptiis, aliquando vero malae voluntati, solidaminis ac cooperationis defectui, quinimmo et simultati, eorum qui inducti sunt vel ex officio vocati uti testes. Nonnumquam demum testimoniorum absentia praeiudicatae opinioni abiudicanda est aulam Tribunalis quacumque de causa ingredi dedecus inferre universis proxima cognatione coniunctis illosque valde dehonestare" 61 .

La célebre alocución del cardenal Felici del 21 febrero 1977 reflejaba la opinión común de los canonistas: sabemos que testis unus testis nullus, a no ser que sea cualificado... pero tal presunción, establecida en el canon 1791 $\$ 1$, puede ser y de hecho ha sido superada en la práctica gracias al concurso de otras pruebas, de por sí quizás insuficientes, pero que han dado valor y fuerza probatoria a la deposición de un solo testigo ${ }^{62}$.

5. Acerca del valor de los testimonios la jurisprudencia rotal romana es igualmente iluminadora en relación a los diferentes capítulos de nulidad. La confesión extrajudicial de la parte simuladora que proviene en juicio a través

${ }^{59}$ Coram Funghini, Romana, diei 28 martii 1990, ARRT. Dec., LXXXII, p. 241242, n. 4 .

${ }^{60}$ Coram Serrano, Tokien., diei 18 aprilis 1975, ARRT. Dec., LVII, p. 328, n. 9.

${ }^{61}$ Coram Funghini, Romana, diei 28 martii 1990, cit. (n. 59).

${ }^{62}$ L'Osservatore Romano, 4 marzo 1977, cit. in una coram Masala, 14 diciembre 1982, ARRT. Dec., LXXIV, p. 633, n. 10. 
de los testimonios de los testigos en relación a la confesión de la parte que ha simulado tiene mayor eficacia probatoria, más que las declaraciones de las partes valen sus confesiones extrajudiciales hechas a testigos en tiempo non suspecto.

En las causas por simulación, las deposiciones de los testigos que refieren en juicio la confesión extrajudicial de la parte simulante tienen que ser valoradas a la luz de la causa simulandi, sea próxima que remota ${ }^{63}$. La misma confesión extrajudicial tiene que ser circunstanciada y el testigo correctamente informado ${ }^{64}$.

A veces la cualidad complesiva de la prueba testimonial aparece más bien débil o por haber conocido las partes solo tardíamente o por la fuente principal de su conocimiento: ab alios y no de ciencia directa, o porque no aportan confirmaciones ciertas y con hechos, es decir, circunstanciadas que prueben la reserva antivinculística de la parte simulante (cánones 1574 ss., artículos 193 DC.).

Particular valor se atribuye a la deposición de los consanguíneos y por ende a los domésticos o a quienes convivieron en el momento de los hechos cuando se trata de metus, aunque a veces, como ya expuesto, la relación de dependencia pueda generar la sospecha: "ipsi, prae aliis, facta matrimonio antecedentia, quae intra domesticos parietes evenerunt, cognoscere poterant: sub eodem tecto enim cum puella continuo degebant, testes oculares sunt factorum quae in iudicio enarrant. Si quid contradictorium igitur vel inverosimile in eorum depositionibus invenitur, iuxta regulas communes iuridicas aestimandum est: ipsi autem ratione famulatus suspicioni obnoxii non sunt" ${ }^{\text {". }}$.

En definitiva, deducciones y conclusiones personales: "profecto, testesprobationem constituunt 'quando referunt verba, facta et circumstantias quae ad rem pertinent et quae propriis sensibus perceperunt, causam reddentes propriae scientiae', minime vero 'quando referunt de proprio iudicio vel credulitate, de propria opinione vel interpretatione etsi firma et validis rationibus suffulta, quia testes testificari deben non iudicare' (decr. c. Giannecchini, 26 februarii 1980, n. 2: SRR, vol. LXXII, p. 148)"66.

"Testes ergo in excussione coram Iudices referant, oportet, dicta simulantis et circumstantias matrimonii, non proprios sensus et opiniones. Non sufficiunt nudae testium assertiones se hoc vel illud audivisse contra prolem et fidem aut

${ }^{63}$ Coram Corso, diei 16 novembris 1988, inédita; coram Civili, diei 23 octobris 1991, ARRT. Dec., LXXXIII, p. 586, n. 10.

${ }^{64}$ Coram Giannecchini, 22 novembris 1991, inédita.

${ }^{65}$ Coram Prior, diei 11 aprilis 1922, ARRT. Dec., XIV, dec. XI, n. 5.

${ }^{66}$ Coram Stankiewicz, diei 26 martii 1987, ARRT. Dec., LXXIX, p. 148, n. 10. 
matrimonii indissolubilitatem, sed necesse est ut addant quo tempore audierunt, quo loco, a quanam persona, quonam contextu serio aut ioculariter dicto" ${ }^{\text {" }}$.

Una coram Stankiewicz enseña que quien miente incluso una sola vez en procedimientos tan graves como una causa de nulidad matrimonial, no es digno de crédito en dichos contextos: semel mendax, semper mendax ${ }^{68}$. Pero también este principio debe ser aplicado con la máxima cautela; al mismo resulta antitético el que se lee en una coram Parillo: "testis verax in uno, verax in coeteris praesumitur, unde quoadusque invicte non probetur testes ex officio auditos falsa dixisse circa litteras a Mara ante et post nuptias datas, eorum testimonio standum est" 69 . La cautela consiste en síntesis en no deducir la mentira únicamente por la inconstancia o por la vacillatio del testigo, sobre todo si esta o aquella se refiere a una circunstancia accesoria $\mathrm{e}$ incluso no decisiva en la causa.

\section{CoNCLUSIÓN}

1. Decidir y juzgar son actos que implican la conciencia y el conocimiento. No es posible sin conocimiento una decisión según la propia conciencia, porque este juicio tiene que estar motivado por la verdad, a la que se llega con el conocimiento, con la aplicación del intelecto, mientras la intencionalidad de la conciencia tiene que ir dirigida, efectivamente, a conformarse a la verdad conocida.

Un juicio o una decisión judicial comporta, igualmente, poner en acto el conocimiento y la prudencia que no puede ser, sin embargo, esta última independiente de la intencionalidad de la propia conciencia, es decir, la conciencia y la prudencia deben ir a la par, es más, la prudencia tiene que informar y guiar la conciencia. No es posible un juicio justo que no sea prudente.

Decidir y juzgar en la Iglesia reclaman el conocimiento, la conciencia, la prudencia que van aplicadas al acto de juzgar.

Como es obvio, ex natura rei la valoración de los testimonios se deja a la libre apreciación del juez, que tiene como guía su conciencia apoyada en los criterios lógicos y objetivos, reclamados oportunamente por la ley y que como tales conllevan una verdadera obligación moral y jurídica. No se trata de principios de prueba legal, sino de criterios directivos, reglas que puesto que son establecidas en la legislación, constituyen una válida ayuda, aplicadas

\footnotetext{
${ }^{67}$ Coram López Illana, diei 12 decembris 1994, ARRT. Dec., LXXXVI, p. 630, n. 21.

${ }^{68}$ Coram Stankiewicz, diei 22 februarii 1996, ARRT. Dec., LXXXVIII, p. 136, n. 35.

${ }^{69}$ Coram Parillo, diei 20 iunii 1924, ARRT. Dec., XVI, dec. XXVII, n. 14.
} 
indudablemente con espíritu crítico y teniendo en cuenta la concordancia con otros testimonios.

Los criterios de valoración se refieren por un lado a la persona del testigo, a la fuente de las declaraciones; por otra, a algunos elementos o circunstancias significativas, que caracterizan su deposición: ante todo el juez tiene que considerar la persona del testigo, su condición, rectitud que están a la base de su credibilidad. A tal fin se solicitarán ex officio si fuera necesario a personas dignas de fe oportunas informaciones sobre la religiosidad, honestidad, etc. del testigo. Un segundo importante criterio es la fuente de las afirmaciones del testigo. Es necesario tener presente si, en su deposición judicial, el testigo ha mostrado seguridad y constancia, o bien, volubilidad, perplejidad, indecisión, incoherencia. En fin, hay que considerar ulteriormente si la deposición judicial del testigo sea aislada o si al contrario haya otras personas que han afirmado las mismas cosas, o si resulta probada por otros elementos o documentos.

De cualquier modo, todos los criterios de valoración de prueba no contrastan, sin embargo, con el principio del libre convencimiento del juez; su misión es la de dar a éste algunas directivas generales, de ayudarlo con algunos datos desumidos por la doctrina secular "infinitis experimentis et observationibus aucta et cumulata”, en su difícil tarea de crítico.

\section{BIBLIOGRAFÍA}

ARrieta, J. I., La salus animarum quale guida applicativa del diritto da parte deipastori, en Ius Ecclesiae, 12 (2000), pp. 343-374.

Battistelli, L., La bugia (Laterza, Bari, 1923).

Benedicto XVI, "Discurso" a los Prelados Auditores, defensores del vínculo y abogados de la Rota Roma, 28 enero 2006, en AAS., 98 (2006).

Benedicto XVI, "Discurso" al Cuerpo diplomático acreditado ante la Santa Sede, 9 enero 2006, en $A A S$., 98 (2006).

Benedictus PP. XV, "Constitutio Apostolica” Providentissima Mater Ecclesia, 27 maii 1917, Professio Catholicae Fidei, Codex Iuris Canonici, Documenta, Index, en AAS., 9 (1917), Pars II.

Bertolone, V., La salus animarum nell'ordinamento giuridico della Chiesa (Romae, 1987).

Bertone, T., La Chiesa e l'impegno per la giustizia. Legalità, giustizia, moralità, en La giustizia nella Chiesa. Fondamento divino e cultura processualistica (Città del Vaticano, 1997).

Boccalini, T., De unico teste in iure canonico, en Fedele, P. (ed.), Studi di diritto canonico in onore di M. Magliocchetti (Roma, 1974), I.

Caberletti, G., Le dichiarazioni delleparti, en Bonnet, P. A. - Gullo, C. (editores), Il giudizio de nullitá matrimoniale dopo l'istruzione Dignitas connubii, III: Parte dinamica del processo (Città del Vaticano, Libreria Editrice Vaticana, 2008). 
Capograssi, G., Intorno al processo. Ricordando Giuseppe Chiovenda, en Opere (Milano, 1959), V.

Carponi Schitar, D., La menzogna nel processo: no dire false testimonianze (Milano, Giuffrè, 2004).

Corpus Iuris Canonici, Editio lipsiensis secunda post Aemilii Ludouici Richteri curas ad librorum manu scriptorum et editionis romanae fidem recognouit et adnotatione critica instruxit Aemilius Friedberg: Pars prior, Decretum Magistri Gratiani (Lipsiae, 1879, ristampa: Graz 1959).

Corpus Iuris Civilis (recognovit Paulus KRUEger, Berolini, 1867).

Da Sussa, E., Summae Hostiensis, lib. I: De off. iud. (Venetiis, 1581, ristampa Torino, 1965).

Dante, A., De Monarchia (Augustae Taurinorum, 1853), I-III.

De Lanversin, B., Valeur d'un témoignage unique an procès, en L'année canonique, 12 (1968), pp. 364-365.

Del Amo, L., Ad can. 1585, en Lombardia, E. - Arrieta, J. I. (editores), Codice di diritto canonico (Roma, 1986), III.

Ewers, H., Prolusio academica in novo inchoando anno apud Studium Rotale, 6 novembre 1978, en Monitor Ecclesiasticus, 103 (1978).

Fedele, P., Equità. Equità canonica, en Enciclopedia del Diritto (Milano, 1966), XV.

Fedele, P., Nibil aliud est aequitas quam Deus, en Ephemerides Iuris Canonici, 20 (1964).

FELICI, P., Indagine psicologica e cause matrimoniali, en Communicationes, 5 (1973).

Fernández Espinar, R., El principio “testis unus testis nullus” en el Derecho procesal español (Madrid, 1979).

FRANSEN, G., La valeur de la jurisprudence en droit canonique, en La norma en el Derecho canónico (Pamplona, 1979), I.

Grocholewski, Z., La certezza morale come chiave di lettura delle norme processuali, en Ius Ecclesiae, 9 (1997).

Gullo C. - Gullo A., Prassi processuale nelle cause canoniche di nullità del matrimonio ( $2^{a}$ edición, Città del Vaticano, Libreria Editrice Vaticana, 2005).

Gullo, C., I periti e le perizie, en Bonnet, P.A. - Gullo, C. (editor), Il giudizio de nullitá matrimoniale dopo l'istruzione Dignitas connubii, III: Parte dinamica del processo (Città del Vaticano, Libreria Editrice Vaticana, 2008).

HERNÁNDEZ Rodríguez, M. V., Los principios generales de oralidad y escritura en el proceso canónico según la instrucción Dignitas connubii, en Revista de Derecho de la Pontificia Universidad Católica de Valparaíso, 34 (Valparaíso, Chile, $1^{\mathrm{er}}$ semestre de 2010).

Herránz, J., Salus animarum, principio dell'ordinamento canonico, en Ius Ecclesiae, $12(2000)$.

Hervada, J., Il diritto naturale nell'ordinamento canonico, en Ius Ecclesiae, 1 (1989).

IoAnnes Paulus PP. II, "Constitutio Apostolica” Sacrae disciplinae leges, Codex Iuris Canonici promulgatur, "Praefatio", Codex Iuris Canonici, Index, 25 ianuarii 1983, en $A A S .75$ (1983) Pars II.

IoAnnes Paulus PP. II, Ad Romanae Rotae iudices, 1 februarii 1980, en AAS., 72 (1980).

Ioannes Paulus PP. II, Ad Romanae Rotae iudices, 10 februarii 1995, en $A A S$., 87 (1995). 
Ioannes Paulus PP. II, Ad Romanae Rotae iudices, 28 enero 1994, en AAS., 86 (1994).

Ioannes Paulus PP. II, Ad Romanae Rotae iudices, 29 ianuarii 2005, en $A A S$., 97 (2005).

IoAnnes Paulus PP. II, Litt. Enc. Fides et ratio, 14 septembris 1999, en AAS., 91 (1999).

IoAnnes Paulus PP. II, Litt. Enc. Veritatis splendor, 6 augustii 1993, en AAS., 85 (1993).

IsIDORUs, Etymologiarum sive Originum, Libri XX (Oxford, 1911, repr. 1989).

Juan Pablo II, "Discurso" a los Prelados Auditores, defensores del vinculo y abogados de la Rota Roma, 18 enero 1990, en AAS., 82 (1990).

Jullien, Card. A., Juges et avocats des Tribunaux de l'Église (Rome, 1970).

LABANDEIRA, E., Las máximas de experiencia en los procesos canónicos, en Ius canonicum, 29 (1989).

Lefebvre, Ch., Aequitas canonica et periculum animae dans la doctrine de l'Hostiensis, en Ephemerides Iuris Canonici, 8 (1952).

Lefebvre, Ch., Equité canonique et manifestations de volonté, en Actes du Congrès de Droit Canonique (Paris, 1947).

Lefebvre, Ch., Equité, en Dictionnaire de Droit Canonique (Paris, 1953), V.

Llobell, J., La modificación ex officio de la fórmula de la duda, la certeza moral y la conformidad de las sentencias en la instrucción Dignitas connubii, en Ius canonicum, 46 (2006).

Lo Castro, G., Introduzione alla tavola rotonda sulla sentenza di Strasburgo del 20 luglio 2001, en El mismo, La sentenza della Corte Europea dei diritti dell'uomo del 20 luglio 2001 (Milano, 2004).

López Zubillaga, J. L., Sub can. 1469, en Código de Derecho Canónico, ed. bilingüe comentada por los profesores de Derecho Canónico de la Universidad Pontificia de Salamanca (Madrid, BAC, 2008).

López Zubillaga, J. L., Sub can. 1560, en Código de Derecho Canónico, ed. bilingüe comentada por los profesores de Derecho Canónico de la Universidad Pontificia de Salamanca (Madrid, BAC, 2008).

Malinverni, A., Oralità, II, en Enciclopedia giuridica (Roma, Treccani, 1990), XXI.

Montini, G.P., L'unità della giurisprudenza: Segnatura Apostolica e Rota Romana, en Gruppo Docenti di Diritto Canonico (editor), I giudizi nella Chiesa: il processo contenzioso e il processo matrimoniale (Milano, Quaderni della Mendola, 1998).

Ortiz, M.Á., Circa l'uso delle presunzioni nelle cause di nullità del matrimonio, en Ius Ecclesiae, 8 (1996).

PAlEARI, E., Considerazioni sul carattere creativo della giurisprudenza canonica in tema di nullità matrimoniale (Urbino, 1979).

Palombi, R., Le presunzioni, Bonnet, P. A. - Gullo, C. (editores), Il giudizio de nullitá matrimoniale dopo l'istruzione Dignitas connubii, III: Parte dinamica del processo (Città del Vaticano, Libreria Editrice Vaticana, 2008).

Paulus PP. VI, "Allocutio" Ad Tribunalis Sacrae Romanae Rotae Decanum, Praelatos Auditores, Officiales et Advocatos, 28 ianuarii 1978, en AAS., 70 (1978).

Pinto Gómez, J. M., La giurisdizione, en P.A Bonnet - C. Gullo (editores), Ilprocesso matrimoniale canonico (Città del Vaticano, Libreria Editrice Vaticana, 1994, nuova edizione riveduta e ampliata). 
Pinto, P. V., I processi nel codice di diritto canonico. Commento sistematico al lib. VII (Città del Vaticano, Libreria Editrice Vaticana, 1993).

PIus PP. XII, "Allocutio" Ad Praelatis Auditoribus ceterisque officialibus et administris Tribunalis Sacrae Romanae Rotae necnon eiusdem Tribunalis Advocatis et Procuratoribus, 3 octobris 1941, en AAS., 33 (1941).

PIUs PP. XII, Ad Praelatos Auditores ceterosque officiales et administros tribunalis $S$. Romanae Rotae necnon eiusdem tribunalis advocatos et procuratores, 1 octobris 1942, en $A A S ., 34$ (1942).

PompedDA, M. F., Il giudice nei tribunali ecclesiastici: norma generale e caso concreto (funzione, competenza professionale, garanzie di indipendenza, giudici laici), en La giustizia nella Chiesa: fondamento divino e cultura processualistica moderna (Città del Vaticano, Libreria Editrice Vaticana, 1997).

Pompedda, M. F., Studi di diritto processuale canonico (Milano, Giuffrè Editore, 1995).

PompedDA, M.F., De usu praesumptionum contra matrimonium valorem, en L'Année canonique, 22 (1978).

Pompedda, M.F., La giurisprudenza come fonte di diritto nell'ordinamento canonico matrimoniale, en Quaderni di Studio Rotale, 1 (1987).

Pontificia Commissio Codici Iuris Canonici Recognoscendo, Communicationes, 11 (1979); 38 (2006).

Pontificium Consilium de legum textibus, Dignitas connubii. Instructio servanda a tribunalibus dioecesanis et interdioecesanis in pertractandis causis nullitatis matrimonii (Romae, 25 ianuarii 2005).

ReINFFENSTUel, A., Ius canonicum universum (Venetiis, 1759).

Rodríguez-Ocaña, R., La tutela del derecho al proceso en las causas de nulidad matrimonial, en Viladrich BATALleR, P. J. (editor), El matrimonio canónico ante el III milenio (Pamplona, 2001).

Thomae Aguinatis, Opera omnia (Alba - Roma, Editiones Paulinae, ed. fotothypica, 1960). 
